\title{
Weak spatial-genetic structure in a native invasive, the southern pine beetle (Dendroctonus frontalis), across the eastern United States
}

\author{
Ryan C Garrick ${ }^{\text {Corresp., } 1}{ }^{1}$, Ísis C. Arantes ${ }^{1}$, Megan B. Stubbs ${ }^{1}$, Nathan P. Havill ${ }^{\text {Corresp. } 2}$ \\ ${ }^{1}$ Department of Biology, University of Mississippi, Oxford, Mississippi, United States \\ 2 Northern Research Station, USDA Forest Service, Hamden, Connecticut, United States \\ Corresponding Authors: Ryan C Garrick, Nathan P. Havill \\ Email address: rgarrick@olemiss.edu, nathan.p.havill@usda.gov
}

The southern pine beetle, Dendroctonus frontalis, is a native pest of pine trees that has recently expanded its range into the northeastern United States. Understanding its colonization, dispersal, and connectivity will be critical for mitigating negative economic and ecological impacts in the newly invaded areas. Characterization of spatial-genetic structure can contribute to this; however, previous studies have reached different conclusions about regional population genetic structure, with one study reporting a weak east-west pattern, and the most recent reporting an absence of structure. Here we systematically assessed several explanations for the absence of spatial-genetic structure. To do this, we developed nine new microsatellite markers and combined them with an existing 24-locus data matrix for the same individuals. We then reanalyzed this full dataset alongside datasets in which certain loci were omitted with the goal of creating more favorable signal to noise ratios. We also partitioned the data based on the sex of $D$. frontalis individuals, and then employed a broad suite of genotypic clustering and isolation-by-distance (IBD) analyses. We found that neither inadequate information content in the molecular marker set, nor unfavorable signal-to-noise ratio, nor insensitivity of the analytical approaches could explain the absence of structure. Regardless of dataset composition, there was little evidence for clusters (i.e., distinct geo-genetic groups) or clines (i.e., gradients of increasing allele frequency differences over larger geographic distances), with one exception: significant IBD was repeatedly detected using an individual-based measure of relatedness whenever datasets included males (but not for female-only datasets). This is strongly indicative of broad-scale female-biased dispersal, which has not previously been reported for $D$. frontalis, in part owing to logistical limitations of direct approaches (e.g., capture-mark-recapture). Weak spatial-genetic structure suggests long-distance connectivity and that gene flow is high, but additional research is needed to understand range expansion and outbreak dynamics in this species 
using alternate approaches. 


\title{
1 Weak spatial-genetic structure in a native invasive, the
}

\section{2 southern pine beetle (Dendroctonus frontalis), across}

\section{3 the eastern United States}

4

5

\author{
Ryan C. Garrick ${ }^{1 *}$, Ísis C. Arantes ${ }^{1}$, Megan B. Stubbs ${ }^{1}$, Nathan P. Havill2* \\ ${ }^{1}$ Department of Biology, University of Mississippi, Oxford, MS 38677, USA \\ ${ }^{2}$ USDA Forest Service, Northern Research Station, 51 Mill Pond Road, Hamden, CT 06514, \\ USA
}

Corresponding Authors:

Ryan C. Garrick*

Department of Biology, University of Mississippi, Oxford, MS 38677, USA

Email address: rgarrick@,olemiss.edu

Nathan P. Havill*

USDA Forest Service, Northern Research Station, Hamden, CT 06514, USA

Email address: nathan.p.havill@usda.gov

\section{Abstract}

The southern pine beetle, Dendroctonus frontalis, is a native pest of pine trees that has recently expanded its range into the northeastern United States. Understanding its colonization, dispersal, and connectivity will be critical for mitigating negative economic and ecological impacts in the newly invaded areas. Characterization of spatial-genetic structure can contribute to this; however, previous studies have reached different conclusions about regional population genetic structure, with one study reporting a weak east-west pattern, and the most recent reporting an absence of structure. Here we systematically assessed several explanations for the absence of spatial-genetic structure. To do this, we developed nine new microsatellite markers and combined them with an existing 24-locus data matrix for the same individuals. We then reanalyzed this full dataset alongside datasets in which certain loci were omitted with the goal of creating more favorable signal to noise ratios. We also partitioned the data based on the sex of $D$. frontalis individuals, and then employed a broad suite of genotypic clustering and isolation-bydistance (IBD) analyses. We found that neither inadequate information content in the molecular marker set, nor unfavorable signal-to-noise ratio, nor insensitivity of the analytical approaches could explain the absence of structure. Regardless of dataset composition, there was little 
37 evidence for clusters (i.e., distinct geo-genetic groups) or clines (i.e., gradients of increasing

38

39

40

41

42

43

44

45

46

47

48

49

50

51

52

53

54

55

56

57

58

59

60

61

62

63

64

65

66

67

68

69

70

71

72

73

74

75

76

allele frequency differences over larger geographic distances), with one exception: significant IBD was repeatedly detected using an individual-based measure of relatedness whenever datasets included males (but not for female-only datasets). This is strongly indicative of broad-scale female-biased dispersal, which has not previously been reported for $D$. frontalis, in part owing to logistical limitations of direct approaches (e.g., capture-mark-recapture). Weak spatial-genetic structure suggests long-distance connectivity and that gene flow is high, but additional research is needed to understand range expansion and outbreak dynamics in this species using alternate approaches.

\section{Introduction}

The southern pine beetle, Dendroctonus frontalis (Zimmermann 1868), is an economically important pest of pine trees across eastern North America. Outbreaks have been particularly devastating to hard pines (Gernandt et al. 2005), and multimillion-dollar losses in timber and pulpwood have been recorded (Price et al. 1997; Pye et al. 2011). The species' impacts are now moving north, with pitch pine ecosystems in northeastern North America newly at risk (Lesk et al. 2017; Dodds et al. 2018). Given the destruction that can be caused by $D$. frontalis, and the potential for this species to continue extending its range northward owing to a warming climate, a deeper understanding of the population biology of this beetle, including development and application of molecular tools that can provide insights into dispersal, connectivity, and local mating dynamics, is of immediate importance.

Owing to the pest status of Dendroctonus frontalis, its natural history and population ecology are relatively well understood. All life stages are either fully or partly dependent on the inner bark or phloem of the host tree (Hain et al. 2011). Initially, adult pioneer female beetles are attracted to odors from stressed host trees (e.g., owing to crowding, drought, disease, lightning strikes, or other storm damage), and upon arrival by flight, they initiate an attack and release aggregation pheromones that attract males (Sullivan 2011). Monogamous reproduction typically occurs in nuptial chambers within a newly attacked tree, although some females arrive already gravid. Up to 30 eggs are deposited in serpentine galleries that are excavated by the female parent, who also deposits mycangial fungal spores in the galleries, leading to fungal growth that provides nutritional sustenance to the early stage larval offspring. After developing to the adult stage, offspring emerge from the outer bark of the tree, and then disperse to nearby hosts, which they attack (Hain et al. 2011). The combination of tree odors and aggregation pheromones can stimulate a mass attack that results in "infestation spots" that enlarge within a forest (Sullivan 2011). Such large-scale irruptions cause widespread pine tree morality among healthy trees. These epidemic outbreak years have occurred at irregular intervals ranging from every 5-10 years from the early 1970s to 2000s in the species' native range in the south, where as many as nine overlapping generations per year can be completed. Historically, climatic conditions in the 
77 northern regions prevent more than just a few generations per year, with the species' latitudinal

78 range limit thought to be constrained by winter lows, where temperatures of $-16^{\circ} \mathrm{C}$ cause almost 79 100\% mortality (Hain et al. 2011).

80

81

82

There are several reasons to expect spatial-genetic structure across the range of $D$. frontalis in the eastern United States. For example, its distribution spans the southern Appalachian Mountains - a well-known biogeographic and genetic barrier for diverse species (Soltis et al. 2006), including arthropods (Garrick 2011). Also, given that $D$. frontalis is native to the southern United States, with a broad geographic range that extends south to Honduras and west to Arizona, there should have been ample time for such structure to evolve. Capture-markrecapture and flight mill studies have estimated mean dispersal distances of $0.5 \mathrm{~km}$ to $3.4 \mathrm{~km}$ (Turchin \& Thoeny 1993; Kinn et al. 1994). While this is considered quite a long distance because of the species' small size $(\leq 3 \mathrm{~mm})$, given its expansion into the northeastern United States over the past decade or more via source-sink stepping-stone dynamics, genetic isolationby-distance (IBD) might be detectable. Indeed, earlier work by Schrey et al. (2011) identified a weak east-west division roughly coinciding with the southern Appalachian Mountains, as well as IBD across the eastern United States, using eight microsatellite loci.

Somewhat surprisingly, a recent investigation of spatial-genetic structure in $D$. frontalis by Havill et al. (2019) found broad-scale differentiation between eastern and western North America but did not detect distinct geo-genetic groups nor IBD within eastern North America. The discrepancy with earlier findings is not clearly attributable to differences in the underlying genetic marker set, or the extent of geographic sampling. Havill et al. (2019) used 24 microsatellite loci that included the eight loci from Schrey et al. (2011), and the maximum pairwise distances among collection localities were very similar $(1658 \mathrm{~km}$ vs. $1513 \mathrm{~km}$, respectively). Also, in both studies, per-site sample sizes were quite large (typically $\geq 25$ individuals). Thus, it would seem that biologically meaningful genetic distance estimates should have been attainable. From an applied management perspective, it is important to reconcile these contrasting inferences about spatial-genetic structure among $D$. frontalis in eastern North America because they have different ramifications for impacts upon pine forest ecosystems in newly colonized regions. For example, if distinct genetic clusters exist, multiple gene pools may converge and recombine at the wave front, producing an invasive population with elevated genetic variation and adaptive potential (e.g., Kolbe et al. 2004). Conversely, if the species is essentially panmictic across eastern North America, then the risk of rapid adaptive evolution (e.g., leading to larger population sizes and/or faster expansion speeds in novel environments; Szücs et al. 2017) may be lowered, and mitigation measures previously developed for outbreaks in the native range should be readily transferable to the northeastern United States. That said, forecasting responses to novel climates and associated no-analog communities is challenging (Williams \& Jackson 2007), likely necessitating adaptive management. 
117

118

119

120

121

122

123

124

125

126

127

128

129

130

131

132

133

134

135

136

137

138

139

140

141

142

143

144

145

146

147

148

149

150

151

152

153

154

155

156

157

There are several plausible explanations for an unexpected absence of clusters or clines. Some can be broadly classified as technical issues, such as inadequate information content or unfavorable signal-to-noise ratio in the molecular marker set, and/or insensitivity of the chosen analytical approaches or violation of key assumptions. Alternatively, species-specific biological phenomena may mask or overwrite signatures of spatial-genetic structure. For example, when using biparentally inherited markers, a life history trait such as sex-biased dispersal could prevent detection of philopatry that is exhibited by only half of the members of a population. Likewise, a demographic event such as recent rapid range expansion could create nonequilibrium conditions that re-partition genetic variation (perhaps ephemerally) to be consistent with broad-scale panmixia (i.e., similar to impacts of postglacial expansion into newly available habitats; Hewitt 1996, 2004, but see Excoffier \& Ray 2008).

While the explanations for a lack of detectable spatial-genetic structure given above are not mutually exclusive (e.g., technical limitations and biological influences may act concurrently), and acknowledging the potential for genuine panmixia (i.e., a null hypothesis that may be true), the goal here was to systematically explore evidence for each of them. This was approached by augmenting, sub-setting, and reanalyzing Havill et al.'s (2019) dataset.

Specifically, we enhanced overall information content by developing and screening additional microsatellite loci, and elevated signal over noise either by identifying and omitting loci most likely to be compromised by null alleles and homoplasy, or following Russello et al. (2012), by retaining only those loci that showed the greatest magnitude of differentiation among sampling sites. For each of these, we also created male-only and female-only partitions of the data. To circumvent potential analytical inefficiencies and/or restrictive assumptions, we used a suite of methods/metrics that each leverage different types of signal in the data, thereby reducing the overall risk of false negatives.

Our exploration of the extent to which inferences about the type, and strength, of spatialgenetic structure may be impacted by technical and/or biological factors improves our understanding of the biology of a destructive native invasive species. This work also contributes new molecular markers that can be used to investigate other aspects of the biology of $D$.

frontalis, such as questions about parentage and relatedness, family group structure and kin clustering, as well as inbreeding dynamics.

\section{Materials \& Methods}

General approaches to assess lack of structure

1. Inadequate information content. The power of microsatellites to detect spatial-genetic structure increases as independent loci are added (Allendorf et al. 2013), but in some cases, at least 30 loci may be needed to detect weak structure (e.g., Duchesne \& Turgeon 2012). To address this, nine new microsatellite markers were developed here, and used to genotype the 
158

159

160

161

162

163

164

165

166

167

168

169

170

171

172

173

174

175

176

177

178

179

180

181

182

183

184

185

186

187

188

189

190

191

192

193

194

195

196

197

198

same individuals included in Havill et al.'s (2019) 24-locus data matrix. Briefly, those samples were collected with permission from the U.S. Department of Agriculture Forest Service by numerous colleagues (see field permit statement) between 2013 and 2017, using Lindgren funnel traps baited with frontalin and alpha-pinene. Specimens were identified as $D$. fontalis following Armendáriz-Toledano and Zuñiga's (2017) key, and individual sex was determined based on the presence (female) or absence (male) of a mycangium on the pronotum. The new and old datasets were combined, creating what we refer to as the "augmented dataset."

2. Unfavorable signal-to-noise ratio. The utility of microsatellite data can be compromised by technical artefacts, and/or affected (either negatively of positively) by inherent features of the loci themselves. To reduce overall noise, we omitted loci most likely to suffer from a higher frequency of non-amplifying null alleles and/or allele size homoplasy based on a proxy for potential mutation rate. Herein, this is the "low noise dataset." As an alternative strategy, we attempted to enhance overall signal by retaining only those loci that maximized genetic differentiation, as measured by $F_{\mathrm{ST}}$ (Weir \& Cockerham 1984) among sampling sites. The thresholds for inclusion in this "high signal dataset" was chosen based on observed natural breaks in the distribution of $F_{\mathrm{ST}}$ values.

3. Sex-biased dispersal. Different degrees of site fidelity between males and females can affect detection of population differentiation when using biparentally inherited microsatellite markers. Impacts are most pronounced when sex-specific dispersal rates and distances are highly asymmetric, and when sampling includes many individuals that have dispersed but not yet reproduced (Prugnolle \& de Meeûs 2002). To evaluate this, we analyzed male-only ( $n=185$ individuals from 9 sites) and female-only ( $n=70,8$ sites) partitions, in addition to combined datasets ( $n=255,9$ sites; Figure 1$)$.

4. Insensitivity of analysis, or violation of assumptions. Genotypic clustering methods differ in their incorporation of geo-spatial information, and when differentiation is weak, this impacts accuracy (Chen et al. 2007). Also, sensitivity of IBD analyses can depend on the chosen genetic distance metric (Séré et al. 2017). To at least partly account for this, each of the above datasets were analyzed using several different clustering and IBD approaches that represent different strengths and limitations of a broader suite of existing methods and metrics. That said, we recognize that clusters vs. clines are not mutually exclusive (Rosenberg et al. 2005), and so we interpret these outcomes with caution, and in the context of our sampling limitations.

Development and validation of new microsatellite loci

In the present study, we extended upon the assessment of a suite of microsatellite loci identified by Havill et al. (2019). Specifically, nine additional loci were selected from among those identified using the software QDD (Meglecz et al. 2014) following low coverage whole genome sequencing of one male $D$. frontalis from Homochitto National Forest, Mississippi 
199

200

201

202

203

204

205

206

207

208

209

210

211

212

213

214

215

216

217

218

219

220

221

222

223

224

225

226

227

228

229

230

231

232

233

234

235

236

237

238

(NCBI BioProject Accession Number PRJNA493650). To assess the suitability of these new loci, multiplex polymerase chain reaction (PCR) amplifications were performed for sets of three loci, each with a different 5 ' fluorescent label on the forward primer and mostly non-overlapping allele size ranges (Table 1). Reactions were conducted in $15 \mu \mathrm{L}$ volumes that contained $7.5 \mu \mathrm{L}$

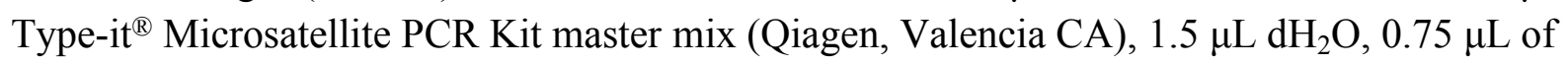
each primer $(10 \mathrm{mM})$, and $1.5 \mu \mathrm{L}$ genomic DNA. The following "touchdown" thermal cycling conditions were used: $95^{\circ} \mathrm{C}$ for $2 \mathrm{~min}(1 \mathrm{cycle}), 95^{\circ} \mathrm{C}$ for $30 \mathrm{sec}, 61^{\circ} \mathrm{C}$ minus $2^{\circ} \mathrm{C}$ per successive cycle for $30 \mathrm{sec}, 72^{\circ} \mathrm{C}$ for $45 \mathrm{sec}(5 \mathrm{cycles}), 95^{\circ} \mathrm{C}$ for $30 \mathrm{sec}, 51^{\circ} \mathrm{C}$ for $30 \mathrm{sec}, 72^{\circ} \mathrm{C}$ for $45 \mathrm{sec}(30$ cycles), and $60^{\circ} \mathrm{C}$ for $30 \mathrm{~min}$ (1 cycle).

Amplified fragments were run on an ABI 3730 sequencer (Life Technologies) with a Liz 500 ladder (Gel Company, San Francisco CA) at Yale University's DNA Analysis Facility on Science Hill. Genotype scoring was performed using GENEIOUS v10.0.5 (Kearse et al. 2012). Following Havill et al. (2019), we assessed Mendelian inheritance patterns for each of the new loci in two local populations (i.e., 27 individuals from Sicily Island, Louisiana, and 28 individuals from Tombigbee, Mississippi). For each locus and population, evidence for departures from Hardy-Weinberg Equilibrium (HWE) were examined via exact tests (Guo \& Thompson 1992), with significance assessed using 10,000 Markov Chain permutations.

Observed $\left(\mathrm{H}_{\mathrm{O}}\right)$ and expected $\left(\mathrm{H}_{\mathrm{E}}\right)$ heterozygosity were also calculated. Independent segregation of alleles among loci was assessed using all $D$. frontalis samples ( 255 individuals) by testing for departures from Linkage Equilibrium (LE) for all possible pairs of 33 loci (i.e., nine reported here, plus 24 from Havill et al. 2019), again using 10,000 Markov Chain permutations. Given that nine different sampling sites were included, Fisher's combined probability test was used to calculate $P$-values across populations for each locus pair. These analyses were performed in GENEPOP v4.5.1 (Rousset 2008), with sequential Bonferroni correction (Holm 1979) of Pvalues associated with LE tests.

$\underline{\text { Identification and omission of loci that may elevate stochastic noise }}$

MICRO-CHECKER v2.2.3 (van Oosterhout et al., 2004) was used to determine whether there was evidence for null alleles, and if so, to estimate their frequencies. For each locus in each local population, a null allele was inferred to exist if there was a significant excess of homozygotes that were evenly distributed across all homozygote classes. This was determined by Fisher's combined probability test, with $P$-values determined using 1,000 permutations. Frequency of the null allele $(r)$ was then was estimated using the method of Chakraborty et al. (1992), which assumes that missing data are not attributable to homozygous nulls, and that populations are panmictic. To identify inbred populations for removal, we relied on the tendency for inbreeding to generate homozygote excess at many loci (cf. locus-specific impacts of null alleles). Here we defined outbred populations as those in which fewer than seven loci (i.e., $<$ $20 \%)$ showed significantly $(P<0.05)$ positive $F_{\text {IS }}$ values. For each locus and population, the null

Peer) reviewing PDF | (2021:01:57327:2:0:NEW 11 Jul 2021) 
239 hypothesis of panmixia was compared to an alternative hypothesis of heterozygote deficiency 240 using a U-test (Rousset \& Raymond 1995), performed in GENEPOP with 10,000 Markov Chain

241

242

243

244

245

246

247

248

249

250

251

252

253

254

255

256

257

258

259

260

261

262

263

264

265

266

267

268

269

270

271

272

273

274

275

276

277

278 permutations. After omitting outbred populations, we rank-ordered the loci based on the level of noise contributed by putative null alleles. To ensure that both prevalence and severity of the null allele at a locus were considered, the $r$ value from each population with a significant excess of homozygotes was summed ( $\left.r_{\text {cumulative }}\right)$.

The number of contiguous repeat units may be a useful proxy for microsatellite mutation rate, given that DNA structure affects the opportunity for slipped-strand mispairing (Bhargava \& Fuentes 2010, and references therein). Here we used the reported positive association between repeat number and mutation rate to identify which loci might be predisposed to having alleles identical in state but not by descent. Briefly, based on one sequence per locus generated during marker development (Schrey et al. 2007; Havill et al. 2019; this study), we first estimated the PCR amplicon length for each locus given the locations of forward and reverse primer annealing sites. Next, the observed number of contiguous repeats was scaled to reflect what should be present within the median-sized allele (i.e., a reference allele identified from the eastern United States gene pool as whole). Rank-ordering of loci based on the potential level of stochastic noise contributed by homoplasy followed the inferred number of repeats of each reference allele.

The omission of loci that may elevate overall noise was based on joint consideration of null alleles and homoplasy. Along each of these two axes, we iteratively omitted the lowest ranked locus one at a time, until a two-sample $t$-test (one-tailed) determined that a significant $(P$ $<0.05$ ) reduction in the mean value of the original metric used for rank-ordering (compared to that of the 33-locus dataset) had been achieved. To assess whether the low noise dataset was comprised of a subset of loci with inadvertently low information content, we calculated Paetkau et al.'s (1995) Probability of Identity (PI; the chance that two individuals randomly drawn from a panmictic population have the same genotype) using GENALEX v6.5 (Peakall \& Smouse 2006, 2012). We then compared mean PI between the reduced vs. full dataset, using a $t$-test as above.

Identification and retention of loci that may enhance overall signal

For species in which population divergence is shallow, "outlier" microsatellite loci (e.g., those displaying unusually strong differentiation, potentially due to effects of divergent selection on linked genomic regions) may be particularly useful for identification of population structure (Russello et al. 2012). This is because recent divergence (e.g., over post-glacial timescales or shorter) may be slow to register in most loci, particularly when it is coupled with large effective populations sizes. To explore the potential benefit of focusing on loci with the strongest signatures of spatial-genetic structure in $D$. frontalis, we calculated global $F_{\mathrm{ST}}$ (Weir \& Cockerham 1984) using the augmented dataset, for each of the 33 loci separately, and then plotted the distribution of these values in rank order. Natural breaks were identified qualitatively, 
279 based on the magnitude of change (i.e., $\Delta F_{\mathrm{ST}}=F_{\mathrm{ST} \text { locus } n}-F_{\mathrm{ST} \text { locus } n+1}$, where $n$ is the rank order 280 position). These breaks defined the thresholds for retention vs. exclusion of loci from the high 281 signal dataset.

282

\section{Genotypic clustering analyses}

To infer the number of natural genetic groups $(K)$ and their members, we analyzed microsatellite datasets using three approaches: STRUCTURE v2.3.4 (Pritchard et al. 2000), BAPS v6.0 (Corander et al. 2003), and Discriminant Analysis of Principal Components (DAPC; Jombart et al. 2010). The first two are Bayesian approaches and assume HWE and LE within "true" clusters. However, STRUCTURE is strictly individual-based and does not make use of geo-referenced samples (although priors on population of origin can be applied), but it has been shown to tolerate clinal variation relatively well (Chen et al. 2007). BAPS can be run using either individuals or groups of individuals as the basic units of analysis, and it explicitly considers spatial coordinates, which can help when differentiation is weak. DAPC can also be used to identify natural groups of individuals a posteriori, but this method does not attribute the underlying cause of such groups to population genetic processes, nor does it incorporate spatial information. In all clustering analyses, we assessed $K$ values from one up to and including the total number of sampling sites (i.e., maximum $K=8$ or 9 , depending on the dataset under consideration).

STRUCTURE. All runs employed the correlated allele frequency and admixture ancestry models. Estimated -ln likelihood scores were obtained for each value of $K$, with 20 replicates each. A burn-in of 50,000 Markov chain Monte Carlo (MCMC) generations and run length of 200,000 MCMC generations were used, with other parameters set as default. The best-fit value of $K$ was chosen using Evanno et al.'s (2005) $\Delta K$ method implemented in STRUCTURE HARVESTER v0.6.94 (Earl \& vonHoldt 2012). However, the $\Delta K$ method is unable to assess support for $K=1$, and it may be subject to bias with respect to identifying only the top (e.g., $K=2$ ) level of hierarchical structure (see Janes et al. 2017). Accordingly, we also used a visual assessment of $\operatorname{Ln} \operatorname{Pr}(\mathrm{X} \mid K)$ plots, from which the smallest $K$ that captured the major structure in the data was accepted, following Pritchard and Wen (2003).

$B A P S$. To enable spatial clustering of individuals, we created non-redundant GPS coordinates via the addition of fine-scale jitter (i.e., a random number at the $4^{\text {th }}$ and $5^{\text {th }}$ decimal places, equivalent to $\leq 11.1 \mathrm{~m}$ at the equator). For spatial clustering of groups of individuals, each of the 8 or 9 sampling locations (depending on the dataset) defined an a priori group, and the original spatial coordinates were used. Accordingly, the complexity of Voronoi tessellations differed considerably between the two approaches. Spatial data were analyzed with associated microsatellite genotype data, with 10 replicates per run. The best-fit $K$ was identified via log marginal likelihood scores (Cheng et al. 2013). 
319

320

321

322

323

324

325

326

327

328

329

330

331

332

333

334

335

336

337

338

339

340

341

342

343

344

345

346

347

348

349

350

351

352

353

354

355

356

357

$D A P C$. Individual-based multilocus microsatellite genotypes were first transformed via principal component (PC) analysis to identify uncorrelated variables to be used for subsequent discriminant analysis. The best-fit number of clusters was determined via $k$-means clustering, with the lowest Bayesian Information Criterion (BIC) score used to choose $K$. Following Miller et al. (2020), an initial preliminary DAPC was conducted to determine the optimal number of PCs to retain, followed by a second final DAPC using the chosen number of PCs. In the initial assessment, the optimal number of PCs was determined using the cross-validation procedure, considering 20 to $300 \mathrm{PCs}$ (in increments of 20) with 30 replicates at each level of PC retention, and $90 \%$ of the data comprising the training set. Pre-defined groups based on sampling location information were used only for the purpose of quantifying the number of de novo clusters that were inferred to be present at a given sampling location. DAPC was implemented using ADEGENET v2.1.2 (Jombart 2008) in R v3.6.1 (R Core Team 2020).

$\underline{\text { Isolation-by-distance analyses }}$

To assess evidence for subtle gradients in genetic variation across the landscape, we conducted IBD analyses of our microsatellite datasets using either sampling sites or individuals as the basic units. The rationale for these two approaches was that population allele frequencies typically can change rather gradually over time and therefore provide insights into historical processes, whereas diploid genotypes are much more labile owing to reshuffling of alleles every generation in sexually reproducing species, and therefore have the potential to closely track recent or on-going processes (Sunnucks 2000; Garrick et al. 2010; Epps \& Keyghobadi 2015).

Population-based metrics. Three measures of genetic distance were used: Cavalli-Sforza and Edwards' (1967) chord distance $\left(D_{\mathrm{c}}\right)$, which has desirable properties for detecting IBD in the presence of null alleles (Séré et al. 2017); Nei's (1972) standard genetic distance $\left(D_{\mathrm{s}}\right)$, which increases linearly with geographic distance if mutation follows an infinite allele model and occurs at a constant rate; and Weir and Cockerham's (1984) estimate of $F_{\text {ST }}$ [linearized as $F_{\mathrm{ST}} /\left(1-F_{\mathrm{ST}}\right)$ following Slatkin $(1995)$, to account for the high mutation rate of microsatellite loci.

Individual-based metrics. Three metrics for genetic similarity were used: the kinship coefficient $\left(\mathrm{D}_{\mathrm{kf}}\right.$, Cavalli-Sforza \& Bodmer 1971); proportion of shared alleles ( $\mathrm{D}_{\mathrm{ps}}$, Bowcock et al. 1994), or relatedness ( $\hat{r}$, Lynch \& Ritland 1999). Briefly, for a given locus, $\mathrm{D}_{\mathrm{kf}}$ is the probability that a randomly chosen allele from one individual is identical-by-descent to that of second individual (summed over all loci and alleles). Conversely, when comparing two mutlilocus genotypes, $\mathrm{D}_{\mathrm{ps}}$ is calculated as number of shared alleles summed over loci / ( $2 \times$ number of loci compared). Unlike the other two metrics, Lynch and Ritland's (1999) methods-of-moments estimator of relatedness makes use of information on population allele frequencies (e.g. a shared rare allele is

Peer] reviewing PDF | (2021:01:57327:2:0:NEW 11 Jul 2021) 
358

359

360

361

362

363

364

365

366

367

368

369

370

371

372

373

374

375

376

377

378

379

380

381

382

383

384

385

386

387

388

389

390

391

392

393

394

395

396

397

considered more likely to be identical-by-descent than a shared common allele). Given that $\hat{r}$ is asymmetrical, following Ritland (2000), we used the average of both directions.

MICROSATELLITE ANALYZER v4.05 (Dieringer \& Schlötterer 2003) was used to calculate $D_{\mathrm{c}}, \mathrm{D}_{\mathrm{kf}}$, and $\mathrm{D}_{\mathrm{ps}}$, whereas GENALEX was used to calculate $D_{\mathrm{s}}, F_{\mathrm{ST}}$ and $\hat{r}$, as well as linear pairwise geographic distance matrices based on latitude and longitude coordinates, using a modified Haversine Formula. For all datasets and distance metrics, the significance of IBD was assessed via Mantel (1967) tests with 999 permutations.

\section{Results}

Development and validation of new microsatellite loci

For the nine new loci developed here, amplification success across all eastern United States $D$. frontalis samples was reasonably high (mean of $4.2 \%$ missing data per locus). Three loci showed significant departures from HWE in the direction of homozygote excess. However, in all cases this was limited to just one of the two local collection sites (Table 1), suggesting that there were no intrinsic issues with allelic inheritance (i.e., the new microsatellite loci appear to be autosomal, diploid, and single copy). Levels of with-population polymorphism were modest (mean of $\sim 4.3$ alleles per new locus for the two exemplar local populations). Across all eastern United States $D$. frontalis samples, there was a mean of 8.1 alleles per new locus (Table 1). Based on our assessment of LE for all 33 loci (528 locus pairs), 22 pairs were significant at the $P$ $<0.05$-level, but none remained so after sequential Bonferroni correction to account for multiple tests. Accordingly, there was no strong evidence for non-independence among loci in the augmented dataset. Preliminary analyses using all loci indicated weak genetic structure among sampling sites $\left(F_{\mathrm{ST}}=0.009, P=0.001\right)$.

$\underline{\text { Identification and omission of loci that may elevate overall noise }}$

Null alleles. Two local populations had seven or more loci with significantly positive $F_{\text {IS }}$ values: Homochitto, MS, and Woolford, MD. These were considered inbred and therefore omitted from consideration when assessing null alleles. MICRO-CHECKER identified 13 loci that may have a null allele (Table 2). However, prevalence was low (i.e., restricted to a single population) for 10 of these. Of the remaining loci, two had null alleles in four populations, and one had nulls in two populations. Across the 20 cases of putative null alleles (out of 33 loci $\times 7$ retained populations $=$ 231 potential cases), mean estimated $r$ was 0.245 (range: $0.139-0.431$ ). Rank-ordering followed by iterative removal revealed that omission of the five worst loci was required to significantly reduce the mean $r$ cumulative value $(t=1.720$, d.f. $=40, P=0.047)$. The removal of these loci did not cause a concomitant reduction in mean information content, as measured by PI $(t=-0.435$, d.f. $=57, P=0.332$ ). 
398

399

400

401

402

403

404

405

406

407

408

409

410

411

412

413

414

415

416

417

418

419

420

421

422

423

424

425

426

427

428

429

430

431

432

433

434

435

436

437

Homoplasy. For 31 loci, the available allele sequence trimmed at the 5' ends of both primers yielded a predicted PCR product that was within the empirically determined size range for eastern United States $D$. frontalis. For two loci with unexpectedly short or long amplicons, an alternative priming site (i.e., a region of high sequence similarity located up or downstream of the original target site) was readily identifiable (Table 3). Three loci constrained two distinct microsatellite regions. These were either composed of different (i.e., compound) repeat motifs located immediately adjacent to one other (locus Dfr-16; Schrey et al. 2007), or the same (i.e., impure) repeat motif interrupted by a 2-bp (locus Dfr-24; Schrey et al. 2007) or 3-bp (locus SPB1534; this study) insertion. In all three cases, only the longest repeat region was used as a proxy for potential for homoplasy. Following re-scaling (see Methods), across 33 loci the average value of the median contiguous number of repeats was 7.6 (range: 4.945-14.901; Table 3 ). The five most concerning loci needed to be removed in order to significantly reduce the number of repeat units $(t=1.819$, d.f. $=50, P=0.037)$, but their omission did not also reduce mean PI $(t=-0.780$, d.f. $=58, P=0.219)$.

Of the two sets of five omitted loci, one (Dfr-24) was common to both approaches used to reduce noise. Accordingly, the largest subset of loci with reduced null allele and homoplasy issues was made up of 24 loci. Reassessment of the impacts of our strategic removal of nine loci to create the low noise dataset showed that the reduction in mean $r_{\text {cumulative remained close to }}$ significant $(t=1.520$, d.f. $=42, P=0.068)$, and so did reduction in mean number of repeats $(t=$ 1.499 , d.f. $=53, P=0.070)$. As before, there was no inadvertent change in mean PI $(t=-1.180$, d.f. $=51, P=0.122)$. Although our low noise dataset happened to contain the same number of loci originally analyzed by Havill et al. (2019), their compositions differed by eight loci.

$\underline{\text { Identification and retention of loci that may enhance overall signal }}$

Based on a visual examination of the $\Delta F_{\text {ST }}$ plot, several inflection points marking pronounced decreases in $F_{\mathrm{ST}}$ among adjacent rank-ordered loci were apparent (Figure 2). Aside from steep declines that would have set a threshold for retention of too few loci for meaningful population genetic analyses (i.e., $\leq 5$ loci), there were two other inflection points: one at the transition from the $10^{\text {th }}$ to $11^{\text {th }}$ ranked locus, and another at the transition from $19^{\text {th }}$ to $20^{\text {th }}$. Accordingly, we created two alternative versions of the high sensitivity dataset. One contained 10 loci with the highest $F_{\mathrm{ST}}$ values, and the other was an expansion of this, where we retained the 19 highest ranked loci (Table 4). The 10-locus and 19-locus high signal datasets contained 3 and 6 loci, respectively, that were not shared with the 24-locus low noise dataset. Compared to Havill et al.'s (2019) original dataset, the 10-locus and 19-locus high signal datasets contained 2 and 5 novel loci, respectively. Ultimately, all datasets analyzed in the present paper differed from each other and from the previous study, thereby enabling meaningful comparisons.

Peer] reviewing PDF | (2021:01:57327:2:0:NEW 11 Jul 2021) 
438 Genotypic clustering analyses

439

440

441

442

443

444

445

446

447

448

449

450

451

452

453

454

455

456

457

458

459

460

461

462

463

464

465

466

467

468

469

470

471

472

473

474

475

476

477

STRUCTURE. Across all 12 datasets (i.e., ADS, LNDS, and HSDS with 10 or 19 loci; males and females combined, or separated) there were five instances where the two alternative approaches for identifying the best-fit value of $K$ were in conflict. In these cases, Pritchard and Wen's (2003) qualitative method inferred $K=1$ whereas Evanno et al.'s (2005) $\Delta K$ method inferred $K=2$, 3, or 4 , depending in the dataset (Table 5; but note that $\Delta K$ is not capable of assessing $K=1$ ). More generally, irrespective of whether there was agreement or conflict between methods, wherever $K>1$ was inferred, the optimal clustering solution almost always contained "ghost clusters" (sensu Guillot et al. 2005; i.e., those for which no individuals were strongly assigned with membership coefficient of $Q>0.50$ ). In some cases, all clusters were nonsensical. For instance, based on $\Delta K$, the best-fit value was $K=3$ for LNDS males plus females, and LNDS females-only, yet not a single individual was strongly assigned; Table 5). Additionally, when $K>1$ there was also an absence of geographic localization of clusters. Ultimately, as with Havill et al.'s (2019) STRUCTURE analysis of a 24-locus $D$. frontalis dataset, our reanalysis using augmented and/or sub-setted datasets did not provide any indications of discrete population structure.

$B A P S$. The optimal partition of geo-referenced molecular data was $K=1$ for all datasets, using both individual- and population-based clustering approaches (Table 5). Given this outcome, we performed post-hoc HWE exact tests in GENEPOP, treating all individuals as members of a single population. Each of the 12 datasets showed highly significant departures from HWE (all $P<0.0005$ ), indicating that eastern United States $D$. frontalis cannot simply be characterized as panmictic.

$D A P C$. Across all datasets, there were only two instances where $K=1$ was inferred (Table 5; but note that DAPC was not intended for this purpose; see Miller et al. 2020). However, wherever $K \geq 2$, there were strong indications that the groups were artifacts rather true reflections of population structure. For example, there were no cases where a given local sampling site contained members of only a single inferred cluster. Indeed, in seven of the datasets with best-fit $K \geq 2$, all sampling sites contained representatives of all inferred clusters (Table 5); such levels of coexistence among putatively distinct gene pools has no plausible biological explanation.

\section{$\underline{\text { Isolation-by-distance analyses }}$}

Population-based metrics. Regardless of which microsatellite dataset was analyzed, or which genetic distance metric was used, no significant IBD was detected (all $P \geq 0.130$; Table 6).

Individual-based metrics. All instances of significant IBD were limited to Lynch and Ritland's (1999) relatedness (note that such relationships are negative). Furthermore, this significant IBD was almost always associated with datasets that included males, with the one exception being the

Peer) reviewing PDF | (2021:01:57327:2:0:NEW 11 Jul 2021) 
478 female-only 19-locus high sensitivity dataset (Table 6). Despite relatively strong significance (all $479 P=0.001$, except for the aforementioned female-only dataset, which had $P=0.031$; Table 6), the 480 nature of relationships between relatedness and geographic distance were consistently weak 481 [augmented dataset with males plus females: slope $=-2 \times 10^{-6}$, correlation coefficient $(r)=0.036$; 482 augmented dataset with males only: slope $=-2 \times 10^{-6}, r=0.037$; low noise dataset with males plus 483 females: slope $=-2 \times 10^{-6}, r=0.020$; low noise dataset with males only: slope $=-2 \times 10^{-6}, r=$ 484 0.030; and even weaker for the 19-locus high signal dataset with females only: slope $=-3 \times 10^{-6}, r$ $485=0.001]$. Overall, these outcomes are consistent with female-biased dispersal; however, males do 486 not appear to be strongly philopatric.

487

488 Discussion

489

490

491

492

493

494

495

496

497

498

499

500

501

502

503

504

505

506

507

508

509

510

511

512

513

514

515

516

517

Spatially explicit population genetic analyses of microsatellite data from invasive insect species can identify the geographic origin(s) and number of independent introductions into newly invaded areas, and provide insights into the relative importance of natural vs. human-mediated dispersal (e.g., fire ants, Ascunce et al. 2011; termites, Perdereau et al. 2013; hemlock woolly adelgid, Havill et al. 2016). These inferences have implications for management, such as enabling targeted control (e.g., of an invasive "bridgehead" population that is the primary source of subsequent spread [Lombaert et al. 2010] and which may have evolved higher invasiveness [Whitney \& Gabler 2008]), or enhanced surveillance of "stowaways" where transportation networks are involved in accelerating spread (e.g., via inadvertent movement of contaminated live plants, wood packing materials, or firewood; Meurisse et al. 2019). Notably, these insights often depend on the existence of discrete populations, yet a long-standing challenge in population genetics is the "clusters vs. clines" problem. This refers to the tendency for clustering methods to fail (or mislead) when structure manifests as continuous gradients of genetic differentiation, and conversely, true signatures of IBD can be distorted if sampling traverses abrupt genetic breaks or is discontinuous and uneven (e.g., Frantz et al. 2009; Bradburd et al. 2018). While clusters and clines are not mutually exclusive (see Rosenberg et al. 2005), an understanding of the predominant form of spatial-genetic structure informs the choice of appropriate analyses for reconstructing population history. In the case of $D$. frontalis, gaining insights into the species' recent and rapid range expansion to the northeastern United States is of considerable interest owing to the economic and ecological damage this may cause. Accordingly, here we systematically explored alternative explanations for the apparent absence of clusters or clines reported by Havill et al. (2019).

\section{Clusters}

Regardless of whether we increased the number of microsatellite loci (augmented dataset) or analyzed subsets of loci with more favorable signal-to-noise ratio (low noise and high signal datasets), no spatially abrupt genetic subdivisions were detected. Using simulations,

Peer) reviewing PDF | (2021:01:57327:2:0:NEW 11 Jul 2021) 
518 Cullingham et al. (2020) showed that in the presence of even quite low levels of on-going gene 519 flow (i.e., migration rate, $m \geq 0.005$ ), the best-fit number of clusters inferred using 520 STRUCTURE may be systematically underestimated, leading to erroneous inferences of $K=1$.

521 Following the recommendations of those authors and others, we compared outcomes across

522 several analytical methods with different assumptions and found that the inferred absence of

523 discrete clusters was robust (Table 5). We interpret this to indicate that either $D$. frontalis does

524 not exhibit discrete population structure, or gene flow is sufficiently high that such structure is

525 not detectable with our data. Other types of molecular markers, such as single nucleotide

526 polymorphisms (SNPs) assayed via sub-genomic sampling methods that are applicable to non-

527 model species (e.g., Elshire et al. 2011) could reveal subtle fine-scale spatial-genetic structure.

528 For example, compared to inferences from microsatellites, SNPs have identified additional

529 structure in the mountain pine beetle, D. ponderosae (Batista et al. 2016; Janes et al. 2018). That

530 said, although only $4 \times$ to $12 \times$ more bi-allelic SNPs than multi-allelic microsatellite loci might

531 offer comparable resolution of population structure (e.g., Liu et al. 2005; but see Haasl \&

532 Payseur 2011 for a potentially much higher ratio), microsatellites have desirable properties for

533 assignment tests, kinship analyses and estimating heterozygosity, and therefore remain valuable

534 (Narum et al. 2008).

535

536 Clines

537

538

539

When using sampling sites as the unit of analysis, we found that microsatellite dataset composition did not impact conclusions about the absence of range-wide gradients of genetic

540 differentiation. This outcome was also robust to the chosen genetic distance metric (Table 6). Range expansion is often considered in the context of a series of founder events that each give

542 rise to new population with reduced genetic variation along the moving wave of advance, leading

543 to genetic differentiation from the source population. However, when range expansion is recent

544 or on-going, multi-directional, and/or effective population sizes are consistently large, there can

545 be a lag time or weakening of bottleneck effects (also see Roques et al. 2012 for an example of

546 how Allee effects at a low-density wave front can prevent successive loss of genetic diversity). Likewise, if occasional long-distance dispersal is involved, new populations can establish in leaps and bounds, far from the parent population (Nichols \& Hewitt 1994; Hewitt 1996, 1999; Ibrahim et al. 1996). Under any of these scenarios, IBD is not expected to be immediately

550

551

552

553

554

555

556

557 detectable. Indeed, the current expansion of $D$. frontalis to the northeastern United States is both recent and on-going: the species spread throughout New Jersey by the mid- to late-2000's, to Long Island in New York by 2014, and was trapped in Connecticut, Rhode Island and Massachusetts by 2015-2016 (Dodds et al. 2018). Effective population sizes certainly have the potential to be very large, but little is known about non-outbreak populations, making it difficult to speculate about whether genetic drift would be a strong driver of allele frequency differences over increasing geographic distances. However, the capacity for long-distance dispersal by $D$. frontalis has been well-documented: this could occur via active flight over several kilometers, or 
558

559

560

561

562

563

564

565

566

567

568

569

570

571

572

573

574

575

576

577

578

579

580

581

582

583

584

585

586

587

588

589

590

591

592

593

594

595

596

597

via passive above-canopy wind-assisted dispersal over tens of kilometers (Jones et al. 2019, and references therein). Ultimately, lack of IBD is not entirely unexpected, at least not in the newly invaded portion of this species' current geographic range. However, other explanations exist. For example, detection of IBD might be scale-dependent, whereby its signal fades at increasingly larger geographic distances owing to an upper bound on the maximum attainable genetic distance (Castric \& Bernatchez 2003). Such non-linearity might be revealed by iterative reanalysis using different distance thresholds (van Strien et al. 2015), provided that straight-line geographic distance (cf. isolation-by-environment; Wang \& Summers 2010) is the primary driver of genetic divergence.

\section{Female-biased dispersal}

Despite overall weak spatial-genetic structure among eastern United States D. fontalis, we did find significant individual-based IBD attributable to males (Table 6). Although this inference of female-biased dispersal was limited to Lynch \& Ritland's (1999) measure of relatedness, it was robust to different compositions of microsatellite loci across datasets. Indeed, this finding is concordant with life history traits of $D$. frontalis. Females are the pioneering sex, who locate a suitable host before recruiting males via release of aggregation pheromones (Jones et al. 2019). Furthermore, females are larger than males, and given that body mass is correlated with stored energy reserves, their greater capacity for flight (mean distance of $3.4 \mathrm{~km} \mathrm{vs.} 2.7 \mathrm{~km}$ for males) in a flight mill experiment was attributed to sexual size dimorphism (Kinn et al. 1994). Notably, the notion that males are not strongly philopatric is supported by capture-markrecapture data, which showed no significant differences in dispersal between the sexes over distances up to $1 \mathrm{~km}$ (Turchin \& Thoeny 1993).

There are several reasons that could explain why individual-based IBD was detectable in our study, yet population-based IBD was not. For instance, this may simply reflect an issue of sample size (i.e., 2,415-32,385 pairwise comparisons among individuals vs. only 28-36 among sampling sites depending on the dataset; but note the elevated pseudo-replication associated with the former). Alternatively, a difference in the timescales over which spatial-genetic structure has evolved and/or is assessed may be responsible. Indeed, individual-based genetic distances may better reflect contemporary processes such as intra-generational dispersal, whereas populationbased metrics primarily measure historical connectivity given that most signal comes from the accumulated multi-generational effects of dispersal and gene flow (Sunnucks 2000; Garrick et al. 2010; Epps \& Keyghobadi 2015). In the context of this study, however, these explanations are plausible only if the other two individual-based genetic distance metrics that we assessed (i.e., $\mathrm{D}_{\mathrm{kf}}$ and $\mathrm{D}_{\mathrm{ps}}$ ) had low power. One potential advantage of Lynch \& Ritland's (1999) $\hat{r}$ is that loci with more alleles - particularly those with rare alleles - provide more information about relatedness, such that highly polymorphic genetic markers such as microsatellites are very powerful (Ritland 2000). That said, this remains speculative, as simulations have shown $\mathrm{D}_{\mathrm{ps}}$ to 
598 be more sensitive than $r$ under a variety of IBD scenarios, albeit under simplified conditions 599 (Shirk et al. 2016).

600

601

Reconciliation with previous work

602

603

604

Our findings for $D$. frontalis are inconsistent with those of Schrey et al. (2011) who

605 reported both clusters and clines, in the form of an east-west division approximately coincident

606 with southern Appalachian Mountains and population-based IBD across the eastern United

607 States. Those authors used eight microsatellite loci, all of which were included in Havill et al.'s

608 (2019) 24-locus dataset, as well as the present study's 33-locus augmented dataset. Generally,

609 trade-offs between the number of loci and number of individuals generally favors adding loci

610 (Landguth et al. 2012), but given the shared loci, it seems unlikely that the marker set alone can account for contrasting inferences. However, geographic and temporal sampling did differ. Whereas Schrey et al.'s (2011) study design included 19 sites with an average of 63 individuals per site (range: 26-100) collected between fall 2004 to spring 2005, ours included 9 sites with an average of 28 individuals (range: $21-31$ ) collected $>10$ years later (i.e., summer 2016 to summer 2017, except for Ponte Vedra, Florida, collected in summer 2013). Thus, although the overall spatial scale of sampling was similar between studies (see Introduction), effort allocation was not. Indeed, Landguth and Schwartz (2014) have shown that the optimal allocation of $n$ individuals for accurate estimation of $F_{\mathrm{ST}}$ changes depending on the extent of gene flow limitation, with misallocations leading to either over- or under-estimation of $F_{\mathrm{ST}}$, depending on the circumstances. Furthermore, direct comparison between studies may be impacted by the fact

621

622

623

624

625

626 that Schrey et al. (2011) sampled $D$. frontalis during years of relatively low population densities (albeit following a significant outbreak in 2001-2002) whereas our specimens were collected at a time of considerable increase in trap captures in Louisiana and Alabama, and an active outbreak in Mississippi (B. Sullivan, pers. comm.).

627

628

629

630

631

632

633

634

635

636

During $D$. frontalis outbreak years, pulse irruptions have unusual population dynamics whereby beetles emerge from infested trees in several waves and inter-tree distance is an important determinant of attack success, with crowded healthy trees being at greater risk owing to the spill-over effects of aggregation pheromones (Hain et al. 2011). Conversely, in endemic (non-outbreak) situations, $D$. frontalis persists at low densities and generally must travel further after emergence to encounter trees already under stress (e.g., from lightning strike damage or disease). Indeed, seasonal differences within a given year can also impact dispersal behavior, whereby individuals have the greatest potential for long-distance dispersal in Fall and the lowest potential in mid-Summer, owing to temporal differences in fat content levels (Turchin \& Thoeny 1993). Ultimately, the impacts of inter- and intra-year differences in sampling across studies may at least partly account for contrasting conclusions about the nature and strength of spatial-genetic structure. 
638

639

640

641

642

643

644

645

646

647

648

649

650

651

652

653

654

655

656

657

658

659

660

661

662

663

664

665

666

667

668

669

\section{0}

671

672

673

674

675

676

677

The idea that preexisting structure may have been "overwritten" either by a change in outbreak status (i.e., from endemic to epidemic) and/or on-going expansion processes underscores the importance of considering both and ecological and geographic context. For example, James et al. (2015) showed that while the spruce budworm (Choristoneura fumiferana), a cyclical irruptive pest in North America, exhibits weak spatial-genetic structure, there is considerable nuance to this general finding. For example, the legacy of high connectivity during past outbreaks can persist for some time afterwards, high admixture can be driven by migrant adults sourced from relatively few sites, and different life stages (i.e., adults vs. larvae) can concurrently exhibit different degrees of spatial genetic structure. Although the periodicity of spruce budworm outbreaks is considerably longer than that of $D$. frontalis ( $\sim 35$ years vs. $\sim 5-10$ years, respectively) and the synchrony of irruptive populations may occur at different spatial scales, there may be considerable similarity in the underlying processes that generate apparent weak spatial-genetic structure. Future work on D. frontalis could attempt to distinguish between migrant and resident individuals, and model range expansion dynamics and associated sourcesink dynamics, explicitly incorporating temporal effects.

\section{Conclusions}

The lack of discrete population differentiation and substantial IBD in D. frontalis in the eastern United States has implications for management as the species' impacts spread north. In contrast to alien pests that invade a region via long distance introduction by human transport, $D$. frontalis is rapidly spreading into a previously unoccupied region contiguous to its native range. For alien species, gene flow between native and alien populations only occurs via additional introductions. Conversely, for $D$. frontalis, the gene flow between long established populations in the southeastern United States and invading populations in New Jersey, New York, and Connecticut is likely to be extensive and on-going. While it is still an open question whether $D$. frontalis had been present in the northeastern areas at low densities but is only now causing impacts due to population increases with less winter mortality, or if it truly represents a recent arrival, the management implications could rely less on looking for differences in beetle genetics, and more on environmental and host tree differences between the south and north. Indeed, this is an approach that seems to be working (Dodds et al. 2018).

\section{Acknowledgements}

We thank USDA Forest Service for beetle specimens, DeAdra Newman for laboratory assistance, Yale University's DNA Analysis Facility on Science Hill for genotyping services, and Brian Sullivan, Dimitrios Avtzis, Marion Javal, and Patrick James for constructive feedback on the paper.

\section{References}


678

679 Allendorf, F.W., Luikart, G., \& Aitken, S.N. (2013). Conservation and the genetics of

680 populations. $2^{\text {nd }}$ ed. John Wiley and Sons, Hoboken, NJ, USA.

681

682 Armendáriz-Toledano, F., \& Zuñiga, G. (2017). Illustrated key to species of genus Dendroctonus

683 (Coleoptera: Curculionidae) occurring in Mexico and Central America. Journal of Insect

684 Science, 17, 34.

685

686 Ascunce, M.S., Yang, C.-C., Oakey, J., Calcaterra, L., Wu, W.-J., Shih, C.-J., Goudet, J., Ross,

687 K.G., \& Shoemaker, D. (2011). Global invasion history of the fire ant Solenopsis invicta.

688 Science, 331, 1066-1068.

689

690 Batista, P.D., Janes, J.K., Boone, C.K., Murray, B.W., \& Sperling, F.A.H. (2016). Adaptive and

691 neutral markers both show continent-wide population structure of mountain pine beetle

692 (Dendroctonus ponderosae). Ecology and Evolution, 6, 6292-6300.

693

694 Bowcock, A.M., Ruiz-Linares, A., Tomfohrde, J., Minch, E., Kidd, J.R., \& Cavalli-Sforza, L.L.

695 (1994). High resolution of human evolutionary trees with polymorphic microsatellites. Nature, $696368,455-457$.

697

698 Bradburd, G.S., Coop, G.M., \& Ralph, P.L. (2018). Inferring continuous and discrete population 699 genetic structure across space. Genetics, 210, 33-52.

700

701

702

Cavalli-Sforza, L.L., \& Bodmer, W.F. (1971). The genetics of human populations. W.H.

Freeman, San Francisco, CA, USA.

703

704

Cavalli-Sforza, L.L., \& Edwards, A.W.F. (1967). Phylogenetic analysis: models and estimation

705 procedures. American Journal of Human Genetics, 19, 233-257.

706

707 Chakraborty, R., De Andrade, M., Daiger, S.P., \& Budowle, B. (1992). Apparent heterozygote

708 deficiencies observed in DNA typing data and their implications in forensic applications. Annals 709 of Human Genetics, 56, 45-57.

710

711 Chen, C., Durand, E., Forbes, F., \& François, O. (2007). Bayesian clustering algorithms

712 ascertaining spatial population structure: a new computer program and a comparison study.

713 Molecular Ecology Notes, 7, 747-756.

714

715 Cheng, L., Connor, T. R., Siren, J., Aanensen, D. M., \& Corander, J. (2013). Hierarchical and

716 spatially explicit clustering of DNA sequences with BAPS software. Molecular Biology and

717 Evolution, 30, 1224-1228. 
718

719

720

721

722

723

724

725

726

727

728

729

730

731

732

733

734

735

736

737

738

739

740

741

742

743

744

745

746

747

748

749

750

751

752

753

754

755

756

757

Corander, J. Waldmann, P., \& Sillanpää, M.J. (2003). Bayesian analysis of genetic

differentiation between populations. Genetics, 163, 367-374.

Critchfield, W.B., \& Little, E.L. Jr. (1966). Geographic distribution of the pines of the world. USDA Forest Service, Miscellaneous Publication 991, Washington, DC.

Dieringer, D., \& Schlötterer, C. (2003). Microsatellite analyser (MSA): a platform independent analysis tool for large microsatellite data sets. Molecular Ecology Notes, 3, 167-169.

Dodds, K.J., Aoki, C.F., Arango-Velez, A., Cancelliere, J., D'Amato, A.W., DiGirolomo, M.F., \& Rabaglia, R.J. (2018). Expansion of southern pine beetle into northeastern forests:

Management and impact of a primary bark beetle in a new region. Journal of Forestry, 116, 178-191.

Duchesne, P., \& Turgeon, J. (2012) FLOCK provides reliable solutions to the "number of populations" problem. Journal of Heredity, 103, 734-743.

Earl, D.A., \& vonHoldt, B.M. (2012). STRUCTURE HARVESTER: a website and program for visualizing STRUCTURE output and implementing the Evanno method. Conservation Genetics Resources, 4, 359-361.

Elshire, R.J., Glaubitz, J.C., Sun, Q., Poland, J.A., Kawamoto, K., Buckler, E.S., \& Mitchell, S.E. (2011). A robust, simple genotyping-by-sequencing (GBS) approach for high diversity species. PLoS ONE, 6, e19379.

Epps, C.W., \& Keyghobadi, N. (2015). Landscape genetics in a changing world: disentangling historical and contemporary influences and inferring change. Molecular Ecology, 24, 60216040 .

Evanno, G., Regnaut, S., \& Goudet, J. (2005). Detecting the number of clusters of individuals using the software STRUCTURE: a simulation study. Molecular Ecology, 14, 2611-2620.

Excoffier, L. \& Ray, N. (2008). Surfing during population expansions promotes genetic revolutions and structuration. Trends in Ecology and Evolution, 23: 347-351.

Frantz, A.C., Cellina, S., Krier, A., Schley, L., \& Burke, T. (2009). Using spatial Bayesian methods to determine the genetic structure of a continuously distributed population: clusters or isolation by distance? Journal of Applied Ecology, 46, 493-505.

Peer) reviewing PDF | (2021:01:57327:2:0:NEW 11 Jul 2021) 
758 Garrick, R.C. (2011). Montane refuges and topographic complexity generate and maintain

759

760

761

762

763

764

765

766

767

768

769

770

771

772

773

774

775

776

777

778

779

780

781

782

783

784

785

786

787

788

789

790

791

792

793

794

795

796

797

invertebrate biodiversity: recurring themes across space and time. Journal of Insect Conservation, 15, 469-478.

Garrick, R.C., Caccone, A., \& Sunnucks, P. (2010). Inference of population history by coupling exploratory and model-driven phylogeographic analyses. International Journal of Molecular Sciences, 11, 1190-1227.

Gernandt, D.S., Dugua, X.A., Vázquez-Lobo, A., Willyard, A., Letelier, A. M., de la Rosa, J.A.P., Piñero, D., \& Liston, A. (2018). Multi-locus phylogenetics, lineage sorting, and reticulation in Pinus subsection Australes. American Journal of Botany, 105, 711-725.

Guillot, G., Estoup, A., Mortier, F., \& Cosson, J.-F. (2005). A spatial statistical model for landscape genetics. Genetics, 170, 1261-1280.

Guo, S.W., \& Thompson, E.A. (1992). Performing the exact test of Hardy-Weinberg proportion for multiple alleles. Biometrics, 48, 361-372.

Haasl, R.J., \& Payseur, B.A. (2011). Multi-locus inference of population structure: a comparison between single nucleotide polymorphisms and microsatellites. Heredity, 106, 158-171.

Havill, N.P., Cognato, A.I., del-Val, E., Rabaglia, R.J., \& Garrick, R.C. (2019). New molecular tools for Dendroctonus frontalis (Coleoptera: Curculionidae: Scolytinae) reveal an east-west genetic subdivision of Early Pleistocene origin. Insect Systematics and Diversity, 3, 2.

Havill, N.P., Griffin, B.P., Andersen, J.C., Foottit, R.G., Justesen, M.J., Caccone, A., D'Amico, V., \& Elkinton, J.S. (In press). Species delimitation and invasion history of the balsam woolly adelgid, Adelges (Dreyfusia) piceae (Hemiptera: Aphidoidea: Adelgidae), species complex. Systematic Entomology.

Hain, F.P., Duehl, A.J., Gardner, M.J., \& Payne, T.L. (2011). Natural history of the southern pine beetle. In: Coulson RN \& Klepzig KD (eds.) Southern Pine Beetle II. General Technical Report SRS-140. U.S. Department of Agriculture Forest Service, Southern Research Station, Asheville, NC, USA.

Havill, N.P., Shiyake, S., Lamb Galloway, A., Foottit, R.G., Yu, G., Paradis, A., Elkinton, J., Montgomery, M.E., Sano, M., \& Caccone, A. (2016). Ancient and modern colonization of North America by hemlock woolly adelgid, Adelges tsugae (Hemiptera: Adelgidae), an invasive insect from East Asia. Molecular Ecology, 25, 2065-2080.

Peer) reviewing PDF | (2021:01:57327:2:0:NEW 11 Jul 2021) 
798 Hewitt, G. (1996). Some genetic consequences of ice ages, and their role in divergence and

799

800

801

802

803

804

805

806

807

808

809

810

811

812

813

814

815

816

817

818

819

820

821

822

823

824

825

826

827

828

829

830

831

832

833

834

835

836

837

838 speciation. Biology Journal of the Linnaean Society, 58, 247-276.

Hewitt, G. (1999). Post-glacial recolonization of European biota. Biology Journal of the Linnaean Society, 68, 87-112.

Hewitt, G.M. (2004). Genetic consequences of climatic oscillations in the Quaternary. Philosophical Transactions of the Royal Society B: Biological Sciences, 359, 183-195.

Holm, S. (1979). A simple sequentially rejective multiple test procedure. Scandinavian Journal of Statistics, 6, 65-70.

Ibrahim, K.M., Nichols, R.A., \& Hewitt, G.M. (1996). Spatial patterns of genetic variation generated by different forms of dispersal during range expansion. Heredity, 77, 282-291.

James, P.M.A., Cooke, B., Brunet, B.M.T., Lumley, L.M., Sperling, F.A.H., Fortin, M.-J., Quinn, V.S., \& Sturtevant, B.R. (2015). Life-stage differences in spatial genetic structure in an irruptive forest insect: implications for dispersal and spatial synchrony. Molecular Ecology, 24, 296-309.

Janes, J.K., Miller, J.M., Dupuis, J.R., Malenfant, R.M., Gorrell, J.C., Cullingham, C.I., \& Andrew, R.L. (2017). The $K=2$ conundrum. Molecular Ecology, 26, 3594-3602.

Janes, J.K., Worth, J.R.P., Batistia, P.D., \& Sperling, F.A.H. (2018). Inferring ancestry and divergence events in a forest pest using low-density single-nucleotide polymorphisms. Insect Systematics and Diversity, 2, 3.

Jombart, T. (2008). adegenet: a R package for the multivariate analysis of genetic markers. Bioinformatics, 24, 1403-1405.

Jombart, T., Devillard, S., \& Balloux, F. (2010). Discriminant analysis of principal components: a new method for the analysis of genetically structured populations. BMC Genetics, 11, 94.

Kearse, M., Moir, R., Wilson, A., Stones-Havas, S., Cheung, M., Sturrock, S., Buxton, S., Cooper, A., Markowitz, S., Duran, C., Thierer, T., Ashton, B., Meintjes, P., \& Drummond, A. (2012). Geneious Basic: an integrated and extendable desktop software platform for the organization and analysis of sequence data. Bioinformatics, 28, 1647-1649.

Kinn, D.N., Perry, T.J., Guinn, F.H., Strom, B.L., \& Woodring, J. (1994). Energy reserves of individual southern pine beetles (Coleoptera: Scolytidae) as determined by a modified phosphovanillin spectrophotometric method. Journal of Entomological Science, 29, 152-163. 
839

840 Kolbe, J.J., Glor, R.E., Schettino, L.R., Lara, A.C., Larson, A., \& Losos, J.B. (2004). Genetic

841 variation increases during biological invasion by a Cuban lizard. Nature, 431, 177-181.

842

843 Landguth, E.L., Fedy, B.C., Oyler-Mccance, S.J., Garey, A.L., Emel, S.L., Mumma, M., 844 Wagner, H.H., Fortin, M.-J., \& Cushman, S.A. (2012). Effects of sample size, number of 845 markers, and allelic richness on the detection of spatial genetic pattern. Molecular Ecology 846 Resources, 12, 276-284.

847

848 Landguth, E.L., \& Schwartz, M.K. (2014). Evaluating sample allocation and effort in detecting 849 population differentiation for discrete and continuously distributed individuals. Conservation 850 Genetics, 15, 981-992.

851

860

862

867

870

873
852

853

854

855

856

857

858

859

861

863

864

865

866

868

869

871

872

874 Meurisse, N., Rassati, D., Hurley, B.P., Brockerhoff, E.G., \& Haack, R.A. (2019). Common

875 pathways by which non-native forest insects move internationally and domestically. Journal of

876 Pest Science, 92, 13-27.

Lesk, C., Coffel, E., D'Amato, A.W., Dodds, K., \& Horton, R. (2017). Threats to North American forests from southern pine beetle with warming winters. Nature Climate Change, 7 , 713-718.

Liu, N., Chen, L., Wang, S., Oh, C., \& Zhao, H. (2005). Comparison of single-nucleotide polymorphisms and microsatellites in inference of population structure. BMC Genetics, 6, S26.

Lombaert, E., Guillemaud, T., Cornuet, J.-M., Malausa, T., Facon, B., \& Estoup, A. (2010). Bridgehead effect in the worldwide invasion of the biocontrol harlequin ladybird. PLoS ONE, 5, e9743.

Lynch, M., \& Ritland, K. (1999). Estimation of pairwise relatedness with molecular markers. Genetics, 152, 1753-1766.

Mantel, N. (1967). The detection of disease clustering and a generalized regression approach. Cancer Research, 27, 209-220.

Meglecz, E., Pech, N., Gilles, A., Dubut, V., Hingamp, P., Trilles, A., Grenier, R., \& Martin, J.F. (2014). QDD version 3.1: a user-friendly computer program for microsatellite selection and primer design revisited: Experimental validation of variables determining genotyping success rate. Molecular Ecology Resources, 14, 1302-1313.

877 
878 Miller, J.M., Cullingham, C.I., \& Peery, R.M. (2020). The influence of a priori grouping on 879 inference of genetic clusters: simulation study and literature review of the DAPC method.

880 Heredity, 125, 269-280.

881

882 Narum, S.R., Banks, M., Beacham, T.D., Bellinger, M.R., Campbell, M.R., Dekoning, J., Elz, 883 A., Guthrie III, C.M., Kozfkay, C., Miller, K.M., Moran, P., Phillips, R., Seeb, L.W., Smith, 884 C.T., Warheit, K., Young, S.F., \& Garza, J.C. (2008). Differentiating salmon populations at 885 broad and fine geographical scales with microsatellites and single nucleotide polymorphisms. 886 Molecular Ecology, 17, 3464-3477.

887

888

889

890 Nichols, R.A., \& Hewitt, G.M. (1994). The genetic consequences of long distance dispersal

891 during colonization. Heredity, 72, 312-317.

892

893

Peakall, R., \& Smouse, P.E. (2006). GenAlEx 6: genetic analysis in Excel. Population genetic

894 software for teaching and research. Molecular Ecology Notes, 6, 288-295.

895

896

897

898

899

Peakall, R., \& Smouse, P.E. (2012). GenAlEx 6.5: genetic analysis in Excel. Population genetic software for teaching and research - an update. Bioinformatics 28, 2537-2539.

900

901

Perdereau, E., Bagnères, A.-G., Bankhead-Dronnet, S., Dupont, S., Zimmermann, M., Vargo, E.L., \& Dedeine, F. (2013). Global genetic analysis reveals the putative native source of the invasive termite, Reticulitermes flavipes, in France. Molecular Ecology, 22, 1105-1119.

902

903

Price, T.S., Dogget, H.C., Pye, J.M., \& Smith, B. (1997). A history of southern pine beetle

904 outbreaks in the southeastern United States through 2004. Georgia Forestry Commission, 905 Macon, GA, USA.

906

907

Pritchard, J.K., Stephens, M., \& Donnelly, P. (2000). Inference of population structure using

908 multilocus genotype data. Genetics, 155, 945-959.

909

910

911

Pritchard, J. K., \& Wen, W. (2003). Documentation for STRUCTURE Software: Version 2.

912 Chicago: University of Chicago Press. Available at:

913 http://web.stanford.edu/group/pritchardlab/software/structure2_1.html.

914 Prugnolle, F., \& De Meeûs, T. (2002). Inferring sex-biased dispersal from population genetic 915 tools: a review. Heredity, 88, 161-165.

916 
917 Pye, J.M., Holmes, T.P., Prestemon, J.P. \& Wear, D.N. (2011). Economic impacts of the 918 southern pine beetle. In: Coulson RN \& Klepzig KD (eds.) Southern Pine Beetle II. General 919 Technical Report SRS-140. U.S. Department of Agriculture Forest Service, Southern Research 920 Station, Asheville, NC, USA.

921

922 R Core Team (2020) R: a language and environment for statistical computing. Version 3.6.1, 923 924

925

926

927

928

929

930

931

932

933

934

935

936

937 Vienna, Austria. URL https://www.R-project.org/.

Ritland, K. (2000). Marker-inferred relatedness as a tool for detecting heritability in nature. Molecular Ecology, 9, 1195-1204.

Roques, L., Garnier, J., Hamel, F., \& Klein, E.K. (2012) Allee effect promotes diversity in traveling waves of colonization. Proceedings of the National Academy of Sciences of the United States of America, 109, 8828-8833.

Rosenberg, N.A., Mahajan, S., Ramachandran, S., Zhao, C., Pritchard, J.K., \& Feldman, M.W. (2005). Clines, clusters, and the effect of study design on the inference of human population structure. PLoS Genetics, 1, e70.

938

939

940

941

942

943

944

945

946

Rousset, F. (2008). Genepop'007: a complete re-implementation of the Genepop software for Windows and Linux. Molecular Ecology Resources, 8, 103-106.

Rousset, F. \& Raymond, M. (1995). Testing heterozygote excess and deficiency. Genetics, 140, $1413-1419$.

947

948

949

Russello, M.A., Kirk, S.L., Frazer, K.K., \& Askey, P.J. (2012) Detection of outlier loci and their utility for fisheries management. Evolutionary Applications, 5, 39-52.

950

951

952

953

954

955

Schrey, N.M., Schrey, A.W., Heist, E.J., \& Reeve, J.D. (2008). Fine-scale genetic population structure of southern pine beetle (Coleoptera: Curculionidae) in Mississippi forests.

Environmental Entomology, 37, 271-276.

Schrey, N.M., Schrey, A.W., Heist, E.J., \& Reeve, J.D. (2011). Genetic heterogeneity in a cyclical forest pest, the southern pine beetle, Dendroctonus frontalis, is differentiated into east and west groups in the southeastern United States. Journal of Insect Science, 11, 110.

Selkoe, K.A., \& Toonen, R.J. (2006). Microsatellites for ecologists: a practical guide to using and evaluating microsatellite markers. Ecology Letters, 9, 615-629.

Peer) reviewing PDF | (2021:01:57327:2:0:NEW 11 Jul 2021) 
956 Séré, M., Thévenon, S., Belem, A.M.G., \& De Meeûs, T. (2017). Comparison of different

957

958

959

960

961

962

963

964

965

966

967

968

969

970

971

972

973

974

975

976

977

978

979

980

981

982

983

984

985

986

987

988

989

990

991

992

993

994

995

genetic distances to test isolation by distance between populations. Heredity, 119, 55-63.

Shirk, A.J., Landguth, E.L., \& Cushman, S.A. (2017). A comparison of individual-based genetic distance metrics for landscape genetics. Molecular Ecology Resources, 17, 1308-1317.

Slatkin, M. (1995). A measure of population subdivision based on microsatellite allele frequencies. Genetics, 139, 457-462.

Soltis, D.E., Morris, A.B., McLachlan, J.S., Manos, P.S., \& Soltis, P.S. (2006). Comparative phylogeography of unglaciated eastern North America. Molecular Ecology, 15, 4261-4293.

Sullivan, B.T. (2011). Southern pine beetle behavior and semiochemistry. In: Coulson RN \& Klepzig KD (eds.) Southern Pine Beetle II. General Technical Report SRS-140. U.S. Department of Agriculture Forest Service, Southern Research Station, Asheville, NC, USA.

Sunnucks, P. (2000). Efficient genetic markers for population biology. Trends in Ecology and Evolution, 15, 199-203.

Szücs, M., Vahsen, M.L., Melbourne, B.A., Hoover, C., Weiss-Lehman, C., Hufbauer, R.A., \& Schoener, T.W.(2017). Rapid adaptive evolution in novel environments acts as an architect of population range expansion. Proceedings of the National Academy of Sciences of the United States of America, 114, 13501-13506.

Turchin, P., \& Thoeny, W.T. (1993). Quantifying dispersal of southern pine beetles with markrecapture experiments and a diffusion model. Ecological Applications, 3, 187-198.

van Oosterhout, C., Hutchinson, W.F., Wills, D.P.M., \& Shipley, P. (2004). Micro-Checker: software for identifying and correcting genotyping errors in microsatellite data. Molecular Ecology Notes, 4, 535-538.

van Strien, M.J., Holderegger, R., \& Van Heck, H.J. (2015). Isolation-by-distance in landscapes: considerations for landscape genetics. Heredity, 114, 27-37.

Wang, I.J., \& Summers, K. (2010). Genetic structure is correlated with phenotypic divergence rather than geographic isolation in the highly polymorphic strawberry poison-dart frog.

Molecular Ecology, 19, 447-458.

Weir, B.S., \& Cockerham, C.C. (1984). Estimating $F$-statistics for the analysis of population structure. Evolution, 38, 1358-1370. 
996

997 Whitney, K.D., \& Gabler, C.A. (2008). Rapid evolution in introduced species, 'invasive traits'

998 and recipient communities: Challenges for predicting invasive potential. Diversity and

999 Distributions, 14, 569-580.

1000

1001 Williams, J.W., \& Jackson, S.T. (2007). Novel climates, no-analog communities, and ecological 1002 surprises. Frontiers in Ecology and the Environment, 5, 475-482.

1003

1004 Zimmermann, C. (1868). Synopsis of the Scolytidae of America north of Mexico. Transactions

1005 of the American Entomological Society, 2, 141-149. 


\section{Table $\mathbf{1}$ (on next page)}

Characterization of microsatellite loci for $D$. frontalis from each of two local populations.

As in Havill et al. (2019), a pig-tail (5'-GTT-3') was added to the $5^{\prime}$ end of each reverse primer (shown below). Abbreviations are: Eastern North America (ENA); observed $\left(H_{0}\right)$ and expected $\left(H_{E}\right)$ heterozygosity; forward $(F)$ and reverse $(R)$ primers. $H_{0}$ values with an asterisk denote loci that showed significant departure from Hardy-Weinberg Equilibrium at the 0.05level. 
Table 1. Characterization of microsatellite loci for $D$. frontalis from each of two local populations. As in Havill et al. (2019), a pig-tail (5'-GTTT-3') was added to the 5' end of each reverse primer (shown below). Abbreviations are: Eastern North America (ENA); observed $\left(H_{O}\right)$ and expected $\left(H_{E}\right)$ heterozygosity; forward $(F)$ and reverse $(R)$ primers. $H_{O}$ values with an asterisk denote loci that showed significant departure from Hardy-Weinberg Equilibrium at the 0.05-level.

\begin{tabular}{|c|c|c|c|c|c|c|c|c|c|c|}
\hline \multirow[t]{2}{*}{$\begin{array}{l}\text { Locus } \\
\text { name }\end{array}$} & \multirow[t]{2}{*}{ Primer sequences 5' to 3' (fluorescent label) } & \multirow[t]{2}{*}{$\begin{array}{l}\text { Repeat } \\
\text { motif }\end{array}$} & \multicolumn{2}{|c|}{$\begin{array}{c}\text { All ENA } \\
\text { populations }\end{array}$} & \multicolumn{3}{|c|}{ Sicily Island, Louisiana } & \multicolumn{3}{|c|}{ Tombigbee, Mississippi } \\
\hline & & & $\begin{array}{c}\text { Allele } \\
\text { size } \\
\text { range } \\
\text { (bp) }\end{array}$ & $\begin{array}{l}\text { No. of } \\
\text { alleles }\end{array}$ & $\mathrm{H}_{\mathrm{O}}$ & $\mathrm{H}_{\mathrm{E}}$ & $\begin{array}{l}\text { No. of } \\
\text { alleles }\end{array}$ & $\mathrm{H}_{\mathrm{O}}$ & $\mathrm{H}_{\mathrm{E}}$ & $\begin{array}{l}\text { No. of } \\
\text { alleles }\end{array}$ \\
\hline SPB4422 & $\begin{array}{l}\text { F: (FAM)-ATCGACTTCGCACGCAAAAC } \\
\text { R: GTTTCCGCTTTCACTCACTTTAATCAT }\end{array}$ & $A C$ & $226-246$ & 7 & 0.259 & 0.236 & 5 & 0.179 & 0.165 & 3 \\
\hline SPB903595 & $\begin{array}{l}\text { F: (NED)-TTTATGTCTATGCCGGATGG } \\
\text { R: GTTTGGACATTGACAAAATCGGAC }\end{array}$ & CAG & $262-278$ & 7 & 0.320 & 0.269 & 2 & 0.250 & 0.433 & 3 \\
\hline SPB180144 & $\begin{array}{l}\text { F: (PET)-ACTAATATTTCAGGTCCGCC } \\
\text { R: GTTTGAGCTACTGAAAATTGCGAC }\end{array}$ & $A C$ & $172-182$ & 6 & $0.185^{\star}$ & 0.294 & 4 & 0.429 & 0.443 & 4 \\
\hline SPB265317 & $\begin{array}{l}\text { F: (FAM)-AAACATGTCGGGGAATCTAC } \\
\text { R: GTTTGTTCATTAGCAGCAGGGATA }\end{array}$ & AT & 376-395 & 10 & 0.593 & 0.707 & 5 & 0.593 & 0.713 & 5 \\
\hline SPB979494 & $\begin{array}{l}\text { F: (NED)-TGACATATGCGACATAAGGG } \\
\text { R: GTTTGAAGTGTTTATTGTGCTCGG }\end{array}$ & ATC & $192-225$ & 8 & 0.630 & 0.502 & 4 & 0.679 & 0.561 & 5 \\
\hline SPB4155 & $\begin{array}{l}\text { F: (PET)-GATGCAGTGAAAGTGGCGTG } \\
\text { R: GTTTGCCGATCTTTACCAACTCAAGC }\end{array}$ & ATG & $95-116$ & 8 & 0.481 & 0.519 & 4 & 0.593 & 0.562 & 4 \\
\hline SPB3702 & $\begin{array}{l}\text { F: (FAM)-AACGCTTCACATTTGCACCG } \\
\text { R: GTTTCATCGGATAATCCTGCGGGA }\end{array}$ & CAC & $93-117$ & 10 & 0.185 & 0.173 & 4 & 0.321 & 0.284 & 4 \\
\hline SPB1278 & $\begin{array}{l}\text { F: (VIC)-TCAGATCTGAGACGACAAGAAAGA } \\
\text { R: GTTTCCGGTCTGCAAATACGAGGT }\end{array}$ & AT & $104-120$ & 7 & 0.259 & 0.233 & 4 & $0.357^{*}$ & 0.390 & 5 \\
\hline SPB1534 & $\begin{array}{l}\text { F: (PET)-CGGGTGAAAGAGTTAGGGGA } \\
\text { R: GTTTGCCCTTACGATCACAGGTACT }\end{array}$ & $\begin{array}{c}\text { (CCA) } \\
\text { GAA(C) } \\
\text { CA })\end{array}$ & $109-133$ & 10 & $0.615^{\star}$ & 0.641 & 6 & 0.643 & 0.645 & 6 \\
\hline
\end{tabular}




\section{Table 2 (on next page)}

MICRO-CHECKER assessment of null alleles and estimates of their frequency $(r)$.

Twenty cases of putative null alleles were detected (marked by an asterisk) across 33 loci and seven outbred population (abbreviations follow Figure 1). For each locus, $r_{\text {cumulative }}$ is the sum of $r$ values from each population with a significant excess of homozygotes, and this was used to rank-order loci from worst $\left(1^{\text {st }}\right)$ to best (equal $14^{\text {th }}$ ). 
Table 2. MICRO-CHECKER assessment of null alleles and estimates of their frequency $(r)$. Twenty cases of putative null alleles were detected (marked by an asterisk) across 33 loci and seven outbred population (abbreviations follow Figure 1). For each locus, $r_{\text {cumulative }}$ is the sum of $r$ values from each population with a significant excess of homozygotes, and this 4 was used to rank-order loci from worst ( $\left.1^{\text {st }}\right)$ to best (equal $\left.14^{\text {th }}\right)$.

\begin{tabular}{|c|c|c|c|c|c|c|c|c|c|}
\hline \multirow[t]{2}{*}{ Locus name } & \multicolumn{7}{|c|}{ Estimated null allele frequency $(r)$ per population } & \multirow[t]{2}{*}{$r_{\text {cumulative }}$} & \multirow[t]{2}{*}{ Locus rank } \\
\hline & $\mathrm{AL}$ & $\mathrm{FL}$ & $\mathrm{GA}$ & LA & MS-Hol & MS-Tom & PA & & \\
\hline SPB2727 & 0.000 & 0.000 & 0.000 & 0.116 & 0.273 & 0.000 & 0.000 & 0.000 & 14 \\
\hline Dfr-09 & 0.000 & 0.043 & 0.000 & 0.021 & 0.000 & 0.071 & 0.000 & 0.000 & 14 \\
\hline Dfr-16 & 0.001 & 0.000 & 0.096 & 0.000 & 0.008 & 0.000 & 0.000 & 0.000 & 14 \\
\hline SPB3731 & 0.000 & 0.000 & 0.140 & 0.008 & 0.000 & 0.104 & 0.000 & 0.000 & 14 \\
\hline Dfr-10 & 0.055 & 0.000 & 0.000 & 0.029 & 0.000 & 0.011 & 0.000 & 0.000 & 14 \\
\hline SPB2313 & 0.080 & 0.046 & 0.033 & 0.000 & 0.156 & 0.005 & 0.002 & 0.000 & 14 \\
\hline SPB0138 & 0.000 & 0.000 & 0.000 & 0.000 & 0.000 & 0.000 & 0.000 & 0.000 & 14 \\
\hline SPB1983 & 0.055 & 0.000 & 0.015 & 0.000 & 0.000 & 0.000 & 0.000 & 0.000 & 14 \\
\hline Dfr-24 & $0.179 *$ & 0.043 & 0.000 & 0.016 & $0.139 *$ & 0.000 & 0.011 & 0.318 & 5 \\
\hline Dfr-14 & 0.093 & 0.000 & 0.000 & 0.000 & 0.000 & 0.082 & 0.000 & 0.000 & 14 \\
\hline Dfr-17 & 0.010 & 0.013 & 0.082 & 0.000 & 0.000 & 0.050 & 0.000 & 0.000 & 14 \\
\hline SPB2613 & 0.033 & $0.327^{*}$ & 0.021 & 0.000 & 0.000 & 0.012 & 0.000 & 0.327 & 4 \\
\hline SPB1230 & 0.020 & 0.000 & 0.000 & 0.000 & 0.000 & 0.000 & 0.000 & 0.000 & 14 \\
\hline Dfr-18 & 0.032 & 0.000 & 0.024 & 0.000 & 0.021 & 0.000 & 0.000 & 0.000 & 14 \\
\hline SPB1875 & 0.000 & 0.009 & 0.000 & 0.000 & 0.000 & 0.000 & 0.000 & 0.000 & 14 \\
\hline SPB3013 & 0.042 & 0.000 & 0.000 & 0.000 & 0.000 & 0.000 & 0.136 & 0.000 & 14 \\
\hline SPB1272 & 0.017 & 0.000 & 0.000 & 0.000 & 0.000 & 0.000 & 0.043 & 0.000 & 14 \\
\hline SPB1284 & 0.000 & 0.041 & 0.000 & 0.000 & $0.248^{*}$ & 0.052 & 0.013 & 0.248 & 7 \\
\hline SPB1242 & 0.044 & 0.000 & 0.000 & 0.044 & 0.000 & 0.142 & 0.000 & 0.000 & 14 \\
\hline SPB2480 & $0.431 *$ & 0.134 & 0.000 & 0.208 & $0.324 *$ & $0.246 *$ & $0.404 *$ & 1.405 & 1 \\
\hline Dfr-06 & 0.048 & 0.044 & 0.046 & 0.054 & 0.069 & 0.099 & 0.054 & 0.000 & 14 \\
\hline SPB1507 & $0.162 *$ & 0.089 & $0.235^{*}$ & 0.085 & $0.197 *$ & 0.094 & $0.249 *$ & 0.843 & 2 \\
\hline SPB2187 & 0.014 & 0.000 & 0.071 & 0.058 & 0.000 & $0.148^{*}$ & 0.064 & 0.148 & 12 \\
\hline SPB1270 & $0.161^{*}$ & 0.106 & 0.000 & 0.000 & 0.156 & 0.000 & 0.000 & 0.161 & 10 \\
\hline SPB4422 & 0.000 & 0.000 & 0.000 & 0.000 & 0.000 & 0.000 & $0.239 *$ & 0.239 & 8 \\
\hline SPB903595 & 0.000 & 0.000 & 0.106 & 0.000 & 0.053 & $0.268^{*}$ & 0.000 & 0.268 & 6 \\
\hline
\end{tabular}




\begin{tabular}{|l|c|c|c|c|c|c|c|c|c|}
\hline SPB180144 & 0.024 & 0.025 & 0.000 & $0.228^{*}$ & 0.083 & 0.016 & 0.012 & 0.228 & 9 \\
\hline SPB265317 & 0.054 & 0.094 & $0.149^{*}$ & 0.088 & 0.000 & 0.092 & 0.083 & 0.149 & 11 \\
\hline SPB979494 & 0.000 & 0.000 & 0.078 & 0.000 & 0.000 & 0.000 & 0.068 & 0.000 & 14 \\
\hline SPB4155 & 0.053 & 0.000 & $0.426^{*}$ & 0.037 & 0.076 & 0.000 & 0.000 & 0.426 & 3 \\
\hline SPB3702 & 0.006 & 0.006 & 0.000 & 0.000 & 0.065 & 0.000 & 0.223 & 0.000 & 14 \\
\hline SPB1278 & 0.000 & 0.000 & 0.000 & 0.000 & 0.073 & 0.044 & 0.000 & 0.000 & 14 \\
\hline SPB1534 & $0.145^{*}$ & 0.000 & 0.000 & 0.021 & 0.026 & 0.002 & 0.069 & 0.145 & 13 \\
\hline
\end{tabular}




\section{Table 3 (on next page)}

Characterization of a proxy for microsatellite mutation per locus.

From each directly sequenced allele, the number of contiguous repeat units was recorded from the longest uninterrupted microsatellite region (imperfect or compound repeats were seen in three loci, marked with $\dagger$ ), and allele length was determined by trimming sequences at the ends of primer annealing sites (alternative priming sites were inferred for two loci, marked with \#). For each locus, all allele sizes observed across Eastern North American (ENA) populations ( $\mathrm{n}=255$ individuals) were used to calculate the median allele size, and the associated number repeat units was extrapolated and then used to rank-order loci from most $\left(1^{\text {st }}\right)$ to least $\left(33^{\text {rd }}\right)$ potential for homoplasy. 
Table 3. Characterization of a proxy for microsatellite mutation per locus. From each directly sequenced allele, the number of contiguous repeat units was recorded from the longest uninterrupted microsatellite region (imperfect or compound repeats were seen in three loci, marked with $\dagger$ ), and allele length was determined by trimming sequences at the ends of primer annealing sites (alternative priming sites were inferred for two loci, marked with \#). For each locus, all allele sizes observed across Eastern North American (ENA) populations ( $n=255$ individuals) were used to calculate the median allele size, and the associated number repeat units was extrapolated and then used to rank-order loci from most $\left(1^{\text {st }}\right)$ to least $\left(33^{\text {rd }}\right)$ potential for homoplasy.

\begin{tabular}{|c|c|c|c|c|c|c|}
\hline \multirow{2}{*}{$\begin{array}{l}\text { Locus } \\
\text { name }\end{array}$} & \multicolumn{3}{|c|}{ One directly sequenced allele } & \multicolumn{2}{|c|}{ ENA population screening } & \multirow[t]{2}{*}{ Locus rank } \\
\hline & $\begin{array}{c}\text { NCBI } \\
\text { accession }\end{array}$ & $\begin{array}{l}\text { No. of contiguous } \\
\text { repeat units }\end{array}$ & Allele length (bp) & $\begin{array}{l}\text { Median allele length } \\
\text { (bp) }\end{array}$ & $\begin{array}{c}\text { Median no. of } \\
\text { contiguous repeat units }\end{array}$ & \\
\hline SPB2727 & PRJNA493650 & 7 & 144 & 141.5 & 6.88 & 19 \\
\hline Dfr-09 & EF126297 & 10 & 109 & 104.5 & 9.59 & 5 \\
\hline Dfr-16 & EF126300 & $11 \dagger$ & 191 & 183 & 10.54 & 3 \\
\hline SPB3731 & PRJNA493650 & 6 & 145 & 142 & 5.88 & 31 \\
\hline Dfr-10 & EF126298 & 13 & 158 & 149.5 & 12.30 & 2 \\
\hline SPB2313 & PRJNA493650 & 9 & 296 & 292.5 & 8.89 & 9 \\
\hline SPB0138 & PRJNA493650 & 6 & $115 \#$ & 116 & 6.05 & 27 \\
\hline SPB1983 & PRJNA493650 & 7 & 143 & 142 & 6.95 & 18 \\
\hline Dfr-24 & EF126305 & $15 \dagger$ & 151 & 150 & 14.90 & 1 \\
\hline Dfr-14 & EF126299 & 9 & 188 & 190 & 9.10 & 8 \\
\hline Dfr-17 & EF126301 & 9 & 122 & 126 & 9.30 & 6 \\
\hline SPB2613 & PRJNA493650 & 7 & 283 & 291.5 & 7.21 & 14 \\
\hline SPB1230 & PRJNA493650 & 7 & 219 & 227.5 & 7.27 & 13 \\
\hline Dfr-18 & EF126302 & 7 & 130 & 136.5 & 7.35 & 12 \\
\hline SPB1875 & PRJNA493650 & 6 & 110 & 118 & 6.44 & 22 \\
\hline SPB3013 & PRJNA493650 & 6 & 154 & 156.5 & 6.10 & 25 \\
\hline SPB1272 & PRJNA493650 & 9 & 263 & 259.5 & 8.88 & 10 \\
\hline SPB1284 & PRJNA493650 & 8 & 130 & 126 & 7.75 & 11 \\
\hline SPB1242 & PRJNA493650 & 6 & 146 & 144 & 5.92 & 30 \\
\hline SPB2480 & PRJNA493650 & 6 & 162 & 164.5 & 6.09 & 26 \\
\hline Dfr-06 & EF126295 & 10 & 139 & 139 & 10.00 & 4 \\
\hline
\end{tabular}




\begin{tabular}{|c|c|c|c|c|c|c|}
\hline SPB1507 & PRJNA493650 & 7 & 146 & 149 & 7.14 & 15 \\
\hline SPB2187 & PRJNA493650 & 6 & 196 & 194 & 5.94 & 29 \\
\hline SPB1270 & PRJNA493650 & 9 & 243 & 246 & 9.11 & 7 \\
\hline SPB4422 & PRJNA493650 & 7 & $244 \#$ & 230 & 6.60 & 21 \\
\hline SPB903595 & PRJNA493650 & 5 & 275 & 272 & 4.95 & 33 \\
\hline SPB180144 & PRJNA493650 & 7 & 174 & 177 & 7.12 & 16 \\
\hline SPB265317 & PRJNA493650 & 6 & 386 & 389 & 6.05 & 28 \\
\hline SPB979494 & PRJNA493650 & 7 & 215 & 205.5 & 6.69 & 20 \\
\hline SPB4155 & PRJNA493650 & 7 & 107 & 108 & 7.07 & 17 \\
\hline SPB3702 & PRJNA493650 & 6 & 109 & 103.5 & 5.70 & 32 \\
\hline SPB1278 & PRJNA493650 & 6 & 108 & 110 & 6.11 & 24 \\
\hline SPB1534 & PRJNA493650 & $6 \dagger$ & 116 & 120.5 & 6.23 & 23 \\
\hline
\end{tabular}




\section{Table 4 (on next page)}

Global $F_{\text {ST }}$ values for each microsatellite locus, calculated across nine sampling sites ( $\mathrm{n}$ $=255$ individuals), and their rank-ordering from highest $\left(1^{\text {st }}\right)$ to lowest $\left(33^{\text {rd }}\right)$. 
1 Table 4. Global $F_{\mathrm{ST}}$ values for each microsatellite locus, calculated across nine sampling sites $(\mathrm{n}=255$ individuals), and 2 their rank-ordering from highest $\left(1^{\text {st }}\right)$ to lowest $\left(33^{\text {rd }}\right)$.

\begin{tabular}{|c|c|c|}
\hline Locus name & Global $F_{\mathrm{ST}}$ & Locus rank \\
\hline SPB2727 & 0.025 & 11 \\
\hline Dfr-09 & 0.027 & 9 \\
\hline Dfr-16 & 0.023 & 15 \\
\hline SPB3731 & 0.035 & 4 \\
\hline Dfr-10 & 0.022 & 18 \\
\hline SPB2313 & 0.014 & 31 \\
\hline SPB0138 & 0.006 & 33 \\
\hline SPB1983 & 0.018 & 25 \\
\hline Dfr-24 & 0.024 & 12 \\
\hline Dfr-14 & 0.019 & 22 \\
\hline Dfr-17 & 0.028 & 8 \\
\hline SPB2613 & 0.018 & 24 \\
\hline SPB1230 & 0.012 & 32 \\
\hline Dfr-18 & 0.017 & 27 \\
\hline SPB1875 & 0.022 & 19 \\
\hline SPB3013 & 0.028 & 7 \\
\hline SPB1272 & 0.027 & 10 \\
\hline SPB1284 & 0.028 & 6 \\
\hline SPB1242 & 0.019 & 23 \\
\hline SPB2480 & 0.064 & 1 \\
\hline Dfr-06 & 0.015 & 29 \\
\hline SPB1507 & 0.017 & 26 \\
\hline SPB2187 & 0.036 & 3 \\
\hline SPB1270 & 0.023 & 16 \\
\hline SPB4422 & 0.023 & 14 \\
\hline SPB903595 & 0.031 & 5 \\
\hline SPB180144 & 0.017 & 28 \\
\hline SPB265317 & 0.023 & 17 \\
\hline SPB979494 & 0.023 & 13 \\
\hline
\end{tabular}




\begin{tabular}{|l|l|c|}
\hline SPB4155 & 0.039 & 2 \\
\hline SPB3702 & 0.021 & 20 \\
\hline SPB1278 & 0.015 & 30 \\
\hline SPB1534 & 0.019 & 21 \\
\hline
\end{tabular}




\section{Table 5 (on next page)}

Outcomes of genotypic clustering using STRUCTURE (i.e., non-spatial, individual-based), BAPS (i.e., spatial, group- or individual-based) and DAPC (i.e., non-spatial, individualbased).

For STRUCTURE analyses, the number of clusters $(K)$ was inferred using both a quantitative (Evanno et al. 2005) and a qualitative (Pritchard \& Wen 2003) approach. The maximum membership coefficient $(Q)$ was used to identify putative "ghost clusters" in cases where the best-fit $K>1$. Means were calculated from either 20 (STRUCTURE) or 10 (BAPS) replicates. For DAPC analyses, abbreviations are Bayesian Information Criterion (BIC) and Principal Components (PCS), and Not Applicable (N/A). Dataset abbreviations are as follows: augmented dataset (ADS; 33 loci), low noise dataset (LNDS; 24 loci), high sensitivity datasets (HSDS; either 10 or 19 loci), males and females $(m+f)$, males only $(m)$, and females only (f). 
Table 5. Outcomes of genotypic clustering using STRUCTURE (i.e., non-spatial, individual-based), BAPS (i.e., spatial, group- or individual-based) and DAPC (i.e., non-spatial, individual-based). For STRUCTURE analyses, the number of clusters $(K)$ was inferred using both a quantitative (Evanno et al. 2005) and a qualitative (Pritchard \& Wen 2003) approach. The maximum membership coefficient $(Q)$ was used to identify putative "ghost clusters" in cases where the best-fit $K>1$. Means were calculated from either 20 (STRUCTURE) or 10 (BAPS) replicates. For DAPC analyses, abbreviations are Bayesian Information Criterion (BIC) and Principal Components (PCs), and Not Applicable (N/A). Dataset abbreviations are as follows: augmented dataset (ADS; 33 loci), low noise dataset (LNDS; 24 loci), high sensitivity datasets (HSDS; either 10 or 19 loci), males and females $(m+f)$, males only (m), and females only (f).

\begin{tabular}{|c|c|c|c|c|c|c|c|c|c|c|c|c|c|}
\hline \multirow{4}{*}{$\begin{array}{l}\text { Microsatellite } \\
\text { dataset }\end{array}$} & \multicolumn{5}{|c|}{ STRUCTURE } & \multicolumn{4}{|c|}{ BAPS } & \multicolumn{4}{|c|}{ DAPC } \\
\hline & \multirow{2}{*}{\multicolumn{2}{|c|}{$\begin{array}{c}\text { Evanno et al. } \\
(2005)\end{array}$}} & \multirow{2}{*}{\multicolumn{2}{|c|}{$\begin{array}{c}\text { Pritchard \& Wen } \\
\text { (2003) }\end{array}$}} & \multirow{3}{*}{$\begin{array}{c}\text { Maximum } \\
Q \text { in each } \\
\text { inferred } \\
\text { cluster }\end{array}$} & \multicolumn{2}{|c|}{ Groups } & \multicolumn{2}{|c|}{ Individuals } & \multirow{3}{*}{$\begin{array}{l}\text { Best- } \\
\text { fit } K\end{array}$} & \multirow[t]{3}{*}{$\mathrm{BIC}$} & \multirow{3}{*}{$\begin{array}{l}\text { No. of } \\
\text { PCs } \\
\text { retained }\end{array}$} & \multirow{3}{*}{$\begin{array}{l}\text { No. of } \\
\text { clusters } \\
\text { per site }\end{array}$} \\
\hline & & & & & & Best- & Mean & Best- & Mean & & & & \\
\hline & $\begin{array}{l}\text { Best- } \\
\text { fit } K\end{array}$ & $\begin{array}{c}\text { Delta } \\
K\end{array}$ & $\begin{array}{l}\text { Best- } \\
\text { fit } K\end{array}$ & $\begin{array}{l}\text { Mean } \\
\operatorname{Ln} P(K)\end{array}$ & & fit $K$ & $\log (m l)$ & & $\log (m l)$ & & & & \\
\hline ADS $m+f$ & 3 & 10.28 & 3 & $\begin{array}{c}- \\
19161.63\end{array}$ & $\begin{array}{c}0.31 \\
0.33,0.94\end{array}$ & 1 & $\begin{array}{c}- \\
19891.68 \\
\end{array}$ & 1 & $\begin{array}{c}- \\
19891.68 \\
\end{array}$ & 2 & 577.66 & 80 & 2 \\
\hline ADS m & 2 & 48.32 & 2 & $\begin{array}{c}- \\
13949.30\end{array}$ & $0.39,0.92$ & 1 & $\begin{array}{c}- \\
14533.15\end{array}$ & 1 & $\begin{array}{c}- \\
14533.15 \\
\end{array}$ & 2 & 419.22 & 120 & 2 \\
\hline ADS $f$ & 2 & 20.73 & 2 & -5204.64 & $0.43,0.87$ & 1 & -5575.48 & 1 & -5575.48 & 1 & 162.61 & N/A & N/A \\
\hline LNDS $m+f$ & 3 & 5.19 & 1 & $\begin{array}{c}- \\
11792.72 \\
\end{array}$ & $\begin{array}{c}0.45 \\
0.46,0.47 \\
\end{array}$ & 1 & $\begin{array}{c}- \\
12153.79 \\
\end{array}$ & 1 & $\begin{array}{c}- \\
12153.79 \\
\end{array}$ & 3 & 451.90 & 80 & 3 \\
\hline LNDS $\mathrm{m}$ & 2 & 87.50 & 2 & -8534.31 & $0.37,0.93$ & 1 & -8861.98 & 1 & -8861.98 & 3 & 329.35 & 40 & 3 \\
\hline LNDS $\mathrm{f}$ & 3 & 6.34 & 1 & -3201.78 & $\begin{array}{c}0.38 \\
0.38,0.43 \\
\end{array}$ & 1 & -3408.28 & 1 & -3408.28 & 1 & 128.88 & N/A & N/A \\
\hline HSDS10 m+f & 3 & 4.98 & 3 & -5345.57 & $\begin{array}{c}0.57 \\
0.67,0.98 \\
\end{array}$ & 1 & -5549.75 & 1 & -5549.75 & 9 & 242.41 & 45 & $8-9$ \\
\hline HSDS10 m & 5 & 2.59 & 5 & -3943.26 & $\begin{array}{c}0.46 \\
0.47 \\
0.55 \\
0.73,0.86\end{array}$ & 1 & -4086.40 & 1 & -4086.40 & 7 & 183.72 & 35 & $5-7$ \\
\hline HSDS10 f & 2 & 0.10 & 1 & -1444.36 & $0.71,0.80$ & 1 & -1529.06 & 1 & -1529.06 & 4 & 71.63 & 20 & $3-4$ \\
\hline HSDS19 m+f & 3 & 20.73 & 3 & $\begin{array}{c}- \\
10933.57\end{array}$ & $\begin{array}{c}0.35 \\
0.35,0.94\end{array}$ & 1 & $\begin{array}{c}- \\
11338.45\end{array}$ & 1 & $\begin{array}{c}- \\
11338.45\end{array}$ & 4 & 432.41 & 80 & 4 \\
\hline
\end{tabular}




\begin{tabular}{|l|c|c|c|c|c|c|c|c|c|c|c|c|c|}
\hline HSDS19 $\mathrm{m}$ & 4 & 2.28 & 1 & -7939.17 & $\begin{array}{c}0.37, \\
0.39, \\
0.45,0.89\end{array}$ & 1 & -8242.20 & 1 & -8242.20 & 3 & 314.69 & 60 & 3 \\
\hline HSDS19 $\mathrm{f}$ & 2 & 2.01 & 1 & -3035.54 & $0.61,0.74$ & 1 & -3234.04 & 1 & -3234.04 & 2 & 125.00 & 25 & 2 \\
\hline
\end{tabular}




\section{Table 6(on next page)}

Outcomes of Mantel tests of the significance of correlation between geographic and genetic distance.

Abbreviations are as follows: augmented dataset (ADS; 33 loci), low noise dataset (LNDS; 24 loci), high sensitivity datasets (HSDS; either 10 or 19 loci), males and females $(m+f)$, males only (m), and females only (f). Significant $P$-values are marked with an asterisk ( $\dagger$, linearized). 
1 Table 6. Outcomes of Mantel tests of the significance of correlation between geographic 2 and genetic distance. Abbreviations are as follows: augmented dataset (ADS; 33 loci), 3 low noise dataset (LNDS; 24 loci), high sensitivity datasets (HSDS; either 10 or 19 loci), 4 males and females $(\mathrm{m}+\mathrm{f})$, males only $(\mathrm{m})$, and females only (f). Significant $P$-values are 5 marked with an asterisk ( $\dagger$, linearized).

\begin{tabular}{|l|c|c|c|c|c|c|}
\hline \multirow{2}{*}{$\begin{array}{l}\text { Microsatellite } \\
\text { dataset }\end{array}$} & \multicolumn{5}{|c|}{ Isolation-by-distance analysis $P$-values } \\
\cline { 2 - 7 } & $D_{\mathrm{c}}$ & $D_{\mathrm{s}}$ & $F_{\mathrm{ST}}{ }^{\dagger}$ & $\mathrm{D}_{\mathrm{kf}}$ & $D_{\mathrm{ps}}$ & $\hat{r}$ \\
\cline { 2 - 7 } & 0.304 & 0.406 & 0.500 & 0.176 & 0.105 & $0.001^{*}$ \\
\hline ADS m+f & 0.488 & 0.343 & 0.420 & 0.133 & 0.128 & $0.001^{*}$ \\
\hline ADS m & 0.130 & 0.403 & 0.150 & 0.127 & 0.053 & 0.282 \\
\hline ADS f & 0.259 & 0.271 & 0.356 & 0.414 & 0.342 & $0.001^{*}$ \\
\hline LNDS m+f & 0.379 & 0.280 & 0.253 & 0.343 & 0.465 & $0.001^{*}$ \\
\hline LNDS m & 0.152 & 0.455 & 0.264 & 0.294 & 0.191 & 0.443 \\
\hline LNDS f & 0381 & 0.380 & 0.357 & 0.330 & 0.243 & $0.001^{*}$ \\
\hline HSDS10 m+f & 0.177 & 0.360 & 0.393 & 0.222 & 0.240 & $0.013^{*}$ \\
\hline HSDS10 m & 0.419 & 0.451 & 0.276 & 0.457 & 0.287 & 0.406 \\
\hline HSDS10 f & 0.464 & 0.390 & 0.451 & 0.332 & 0.505 & $0.001^{*}$ \\
\hline HSDS19 m+f & 0.452 & 0.475 & 0.397 & 0.226 & 0.308 & $0.001^{*}$ \\
\hline HSDS19 m & 0.287 & 0.481 & 0.174 & 0.283 & 0.154 & $0.031^{*}$ \\
\hline HSDS19 f & & & & &
\end{tabular}

6 
Figure 1

Map of eastern North America showing the locations of nine $D$. frontalis sampling sites (numbered yellow dots).

Pie charts associated with each site represent the proportion of males (black) and females (white) in the set of genotyped beetles. The geographic range of the species (green) is based on the distributions of suitable pine host tree species based on Critchfield and Little (1966), modified to reflect the current northern limits of $D$. frontalis. 


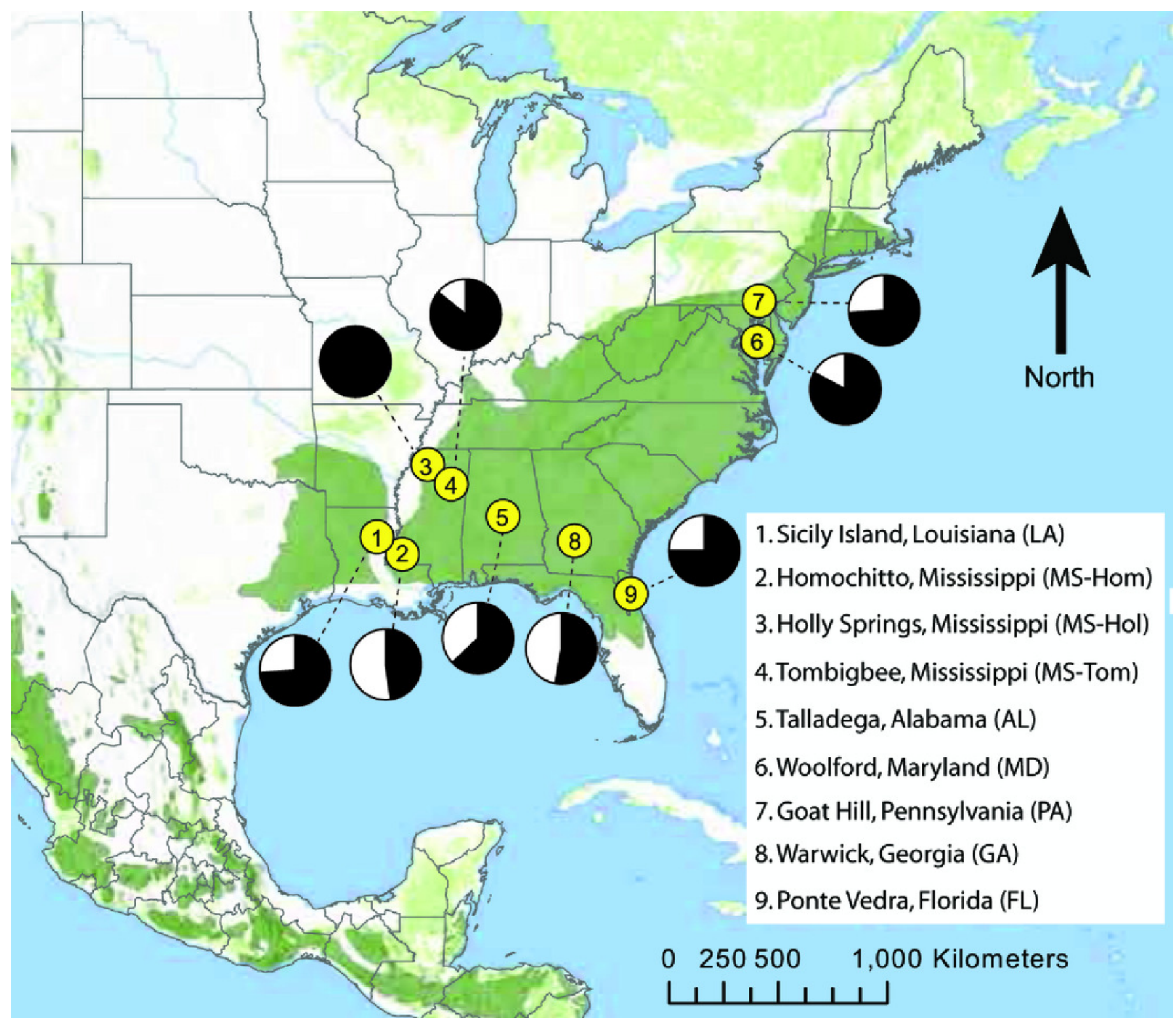


Figure 2

Plot showing the magnitude of reduction in $F_{\mathrm{ST}}$ between adjacent pairs of 27 rankordered loci, used to visually identify inflection points (two open circles) to guide 28 choice of thresholds for the number loci included in the high sensiti

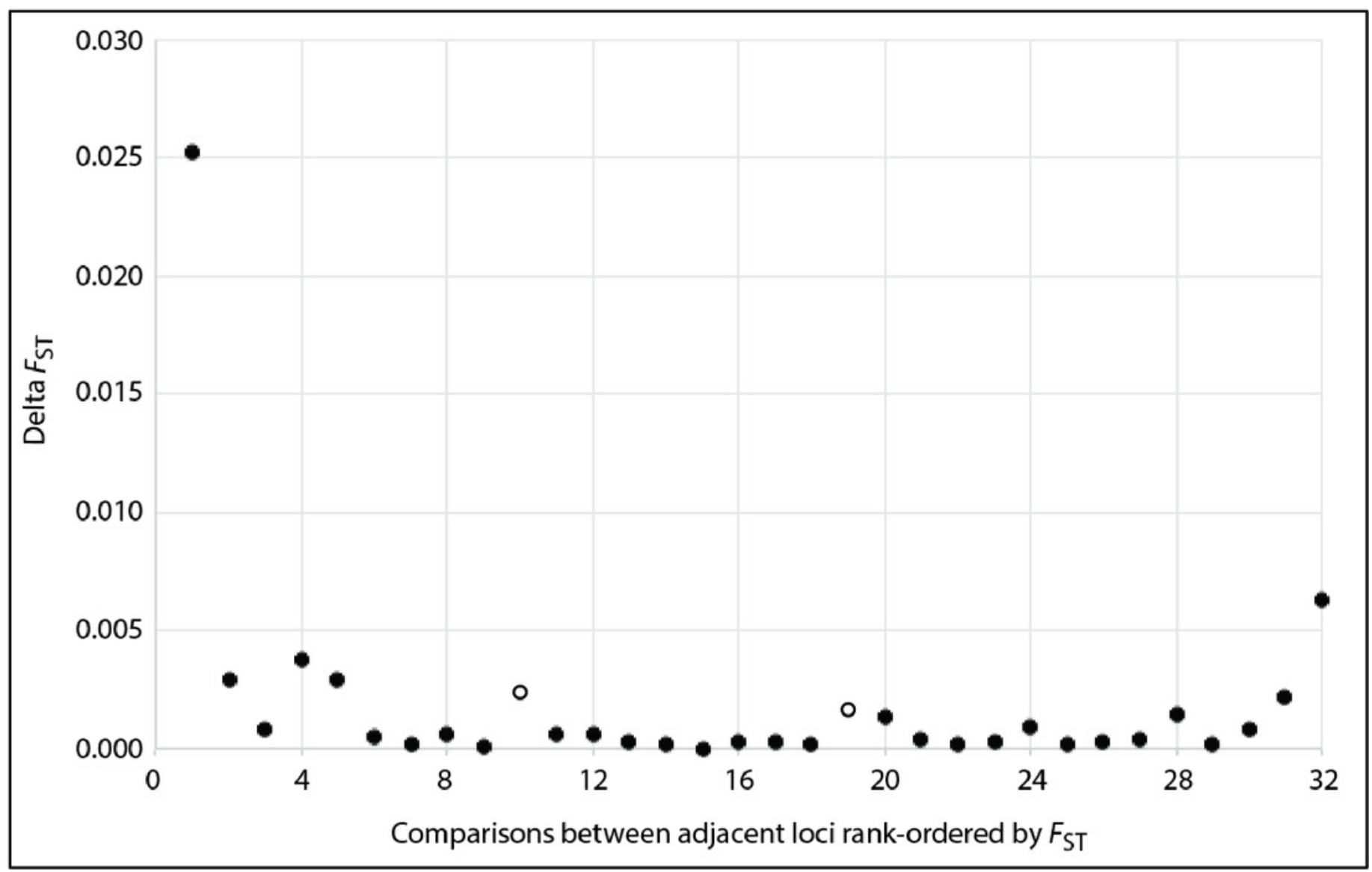

